\title{
Impacts of hydrous manganese oxide on the retention and lability of dissolved organic matter
}

\author{
Jason W. Stuckey ${ }^{1,2^{*}}$, Christopher Goodwin ${ }^{3}$, Jian Wang ${ }^{4}$, Louis A. Kaplan ${ }^{5,6}$, Prian Vidal-Esquivel ${ }^{2}$, \\ Thomas P. Beebe Jr. ${ }^{3}$ and Donald L. Sparks ${ }^{2}$
}

\begin{abstract}
Minerals constitute a primary ecosystem control on organic $C$ decomposition in soils, and therefore on greenhouse gas fluxes to the atmosphere. Secondary minerals, in particular, Fe and Al (oxyhydr)oxides_collectively referred to as "oxides" hereafter-are prominent protectors of organic C against microbial decomposition through sorption and complexation reactions. However, the impacts of $\mathrm{Mn}$ oxides on organic $\mathrm{C}$ retention and lability in soils are poorly understood. Here we show that hydrous $\mathrm{Mn}$ oxide $(\mathrm{HMO})$, a poorly crystalline $\delta-\mathrm{MnO}_{2}$, has a greater maximum sorption capacity for dissolved organic matter (DOM) derived from a deciduous forest composite $\mathrm{O}_{i}, \mathrm{O}_{\mathrm{e}}$, and $\mathrm{O}_{\mathrm{a}}$ horizon leachate ("O horizon leachate" hereafter) than does goethite under acidic ( $\mathrm{pH}$ 5) conditions. Nonetheless, goethite has a stronger sorption capacity for DOM at low initial $\mathrm{C}$ ( $\mathrm{Mn}$ or $\mathrm{Fe}$ ) molar ratios compared to $\mathrm{HMO}$, probably due to ligand exchange with carboxylate groups as revealed by attenuated total reflectance-Fourier transform infrared spectroscopy. X-ray photoelectron spectroscopy and scanning transmission X-ray microscopy-near-edge X-ray absorption fine structure spectroscopy coupled with Mn mass balance calculations reveal that DOM sorption onto HMO induces partial $\mathrm{Mn}$ reductive dissolution and $\mathrm{Mn}$ reduction of the residual $\mathrm{HMO}$. X-ray photoelectron spectroscopy further shows increasing $\mathrm{Mn}(\mathrm{II})$ concentrations are correlated with increasing oxidized $\mathrm{C}(\mathrm{C}=\mathrm{O})$ content $(r=0.78, P<0.0006)$ on the DOM-HMO complexes. We posit that DOM is the more probable reductant of $\mathrm{HMO}$, as $\mathrm{Mn}$ (II)-induced $\mathrm{HMO}$ dissolution does not alter the $\mathrm{Mn}$ speciation of the residual $\mathrm{HMO}$ at pH 5. At a lower C loading $\left(2 \times 10^{2} \mu \mathrm{C} \mathrm{m}^{-2}\right)$, DOM desorption-assessed by $0.1 \mathrm{M} \mathrm{NaH}_{2} \mathrm{PO}_{4}$ extraction—is lower for $\mathrm{HMO}$ than for goethite, whereas the extent of desorption is the same at a higher $\mathrm{C}$ loading $\left(4 \times 10^{2} \mu \mathrm{g} \mathrm{C} \mathrm{m}{ }^{-2}\right)$. No significant differences are observed in the impacts of $\mathrm{HMO}$ and goethite on the biodegradability of the DOM remaining in solution after DOM sorption reaches steady state. Overall, HMO shows a relatively strong capacity to sorb DOM and resist phosphate-induced desorption, but DOM-HMO complexes may be more vulnerable to reductive dissolution than DOM-goethite complexes.
\end{abstract}

Keywords: Soil carbon, Dissolved organic matter, Manganese oxide, Goethite, Organo-mineral associations

\section{Introduction}

Carbon exchange between the Earth's surface and atmosphere is a fundamental regulator of the climate system. Historically an increase in atmospheric temperature has accompanied an increase in atmospheric carbon dioxide $\left(\mathrm{CO}_{2}\right)$ concentration [1]. Carbon exchange within terrestrial systems results from photosynthesis, autotrophic

*Correspondence: jstuckey@multnomah.edu

1 Biology Department, Multnomah University, Portland, OR 97220, USA Full list of author information is available at the end of the article respiration, and microbial respiration [2]. Plant-derived organic $C$ enters the soil through leaf and wood detrital decomposition, throughfall and root exudation. Organic $\mathrm{C}$ may persist in soils for millennia before returning to the atmosphere as $\mathrm{CO}_{2}$ or methane $\left(\mathrm{CH}_{4}\right)$ or being exported to groundwater as dissolved organic carbon (DOC) or dissolved inorganic carbon (DIC) [2]. In fact, the soil $C$ pool is greater than the vegetative and atmospheric $\mathrm{C}$ pools combined [3]. Therefore, a process-level understanding of $C$ storage and fluxes within soils is paramount to projecting future climatic conditions. 
The growing consensus of the predominant means by which soils store and stabilize $\mathrm{C}$ over the long-term is by mineral protection, especially by secondary aluminosilicates and metal oxides [3-9]. Organo-mineral complexes may hinder the efficacy of microbial enzymes to degrade organic $C[6,10,11]$. The major proposed mechanisms of organic $\mathrm{C}$ sorption to minerals include anion exchange (electrostatic interaction), ligand exchange-surface complexation, cation bridging, Van der Waals forces, hydrogen bonding, and hydrophobic interactions [5, 12]. Montmorillonite, for instance, exhibits selective sorption of low molecular weight dissolved organic $\mathrm{C}$ moieties most probably through a relatively weak cation or water bridging mechanism [13]. Metal oxides, on the other hand, may have a greater capacity to sorb $C$ on a mass basis $\left(\mathrm{mg} \mathrm{C} \mathrm{g}^{-1}\right)$ than aluminosilicates do resulting from a higher specific surface area $[10,14,15]$. Further, the importance of $\mathrm{Fe}$ and $\mathrm{Al}$ oxides relative to silicate minerals in stabilizing $C$ generally increases with increased soil development $[16,17]$. Iron oxides are often the most prominent minerals stabilizing organic $\mathrm{C}$ in soils $[9,10,18-20]$. Goethite, for instance, has a strong affinity for DOM through a ligand exchange reaction resulting in Fe-carboxylate bonds on the goethite surface [13, 15]. In acidic forest soils, $\mathrm{Al}$ oxides play a particularly important role in protecting organic $\mathrm{C}$ against microbial degradation through the formation of organo-hydroxyAl complexes during organic litter decomposition, and potentially by $\mathrm{Al}$ toxicity to microbes $[8,21-23]$. Aluminum oxide-DOM complexes may leach into the subsoil ( $\mathrm{B}$ and $\mathrm{C}$ horizons), promoting long-term $\mathrm{C}$ storage [10].

Manganese oxides represent a third class of metal oxides that plays a complex and salient role in the cycling of $C$ within soils and the forest floor [13, 23-25]. Manganese oxides may be enriched in organic $\mathrm{C}$ relative to the bulk soil [26], and poorly crystalline $\delta-\mathrm{MnO}_{2}$ in particular, can serve as a significant reservoir of organic $\mathrm{C}$ in terrestrial environments [27]. In forest ecosystems, the rate of aboveground plant litter decomposition regulates partitioning of organic $\mathrm{C}$ into soil organic matter and $\mathrm{CO}_{2}$ [28]. Factors controlling the plant litter decomposition rate include temperature, moisture, litter quality (e.g., lignin content), and resource availability (e.g., DOC, nutrients, and $\mathrm{Mn}$ ) to the decomposer community [24, 29-37]. Manganese is present initially as $\mathrm{Mn}$ (II) in live foliage and becomes enriched through the litter decomposition process due to carbon loss [29, 38, 39]. Fungi accumulate and oxidize $\mathrm{Mn}(\mathrm{II})$ to $\mathrm{Mn}(\mathrm{III})$, which in turn promotes the oxidative decomposition of litter, regenerating the $M n(I I)$ [24]. Fungi reoxidize $M n(I I)$ to the $\mathrm{Mn}$ (III) through the early stages of decomposition [24]. The $\mathrm{Mn}(\mathrm{III})$ is likely temporarily stabilized in solution by chelating ligands $[24,40]$. In later stages of decomposition, Mn partitions to Mn(III/IV) oxides [24, 41-43].

Manganese oxide-induced organic $\mathrm{C}$ oxidation may cause decomposition to more labile substrates and ultimately to $\mathrm{CO}_{2}[13,23,25,44]$. Manganese oxides may oxidize organic acids, such as pyruvate, but not other acids, such as formate and lactate (at least in the timescale of hours) [44-46]. The oxidative potential of $\mathrm{Mn}$ oxides translates into enhanced microbial decomposition of non-cellulosic polysaccharides, but not of cellulosic polysaccharides or lignin $[23,25]$. Thus, the impact of the complex redox chemistry occurring between $\mathrm{Mn}$ oxides and DOM on the partitioning of $\mathrm{C}$ to $\mathrm{CO}_{2}$ and organic compounds of varying complexity and oxidation state remains poorly defined. Further, the impacts of $\mathrm{Mn}$ oxides on the lability of DOM, and therefore our ability to predict $\mathrm{C}$ exchange between soils-with ubiquitous Mn oxides-and the atmosphere remains elusive.

Much of the work on the interactions between $\mathrm{Mn}$ oxides and organic matter has been performed on model organic compounds [47-51], alkaline extracts (i.e., humic substances) [44, 52, 53], or under alkaline conditions [54]. We are aware of one other study that has studied the extent and mechanism of water-extracted natural DOM sorption to a Mn oxide (i.e., birnessite), showing a low sorption capacity relative to goethite and reductive dissolution of birnessite coupled with oxidative transformation of the DOM through an adsorption mechanism, though the $\mathrm{C}$ moieties involved in the surface complexation and oxidation of DOM are not clear [13]. The extent and mechanism of water-extracted natural DOM sorption onto $\mathrm{HMO}-$ a poorly crystalline $\delta-\mathrm{MnO}_{2}$ analogous to vernadite and a Mn oxide more closely related to biogenic Mn oxides than is birnessite-has not been studied. Nor have the impacts of HMO on the chemical lability and biological degradability of water-extracted natural DOM been examined.

Accordingly, the objectives of this study are to assess the impacts of HMO on the retention, chemical lability, and biological degradability of DOM (as present in an $\mathrm{O}$ horizon leachate) from a deciduous forest soil. Here we use goethite as a positive control in our experiments, as the impacts of goethite on the cycling of forest floorderived DOM are relatively well established $[13,15,19$, 55]. We hypothesize first that HMO will have a lower DOM sorption capacity than goethite due to a lower point of zero charge; secondly, DOM sorbed to HMO will be more labile than that sorbed to goethite, as $\mathrm{Mn}$ oxides are stronger oxidants than Fe oxides, and therefore HMO may reductively dissolve in the presence of DOM; thirdly, the greater oxidative capacity of HMO will increase the biodegradability of DOM remaining in solution post-reaction with HMO compared to that 
reacted with goethite or to the initial, pre-reacted DOM. Here we employ batch sorption and desorption experiments, bioreactor systems, and state-of-the-art analytical techniques including XPS, ATR-FTIR, and synchrotron STXM-NEXAFS, to elucidate the reactions occurring between DOM and the respective metal oxides.

\section{Methods \\ O horizon leachate and mineral preparation and characterization}

The $\mathrm{O}$ horizon leachate was obtained through a water extraction of the $\mathrm{O}$ horizon $\left(\mathrm{O}_{\mathrm{i}}, \mathrm{O}_{\mathrm{e}}\right.$, and $\mathrm{O}_{\mathrm{a}}$; approximately $2 \mathrm{~cm}$ thick) of an Ultisol under a deciduous forest at the Stroud Water Research Center in Avondale, PA predominantly consisting of tulip poplar (Liriodendron tulipifera), American beech (Fagus gradifolia), red maple (Acer rubrum), and red oak (Quercus rubra). The extraction mass ratio was $1: 2(1 \mathrm{~kg}$ field moist litter: $2 \mathrm{~kg}$ DI water), and the suspension was shaken for $90 \mathrm{~h}$ in the dark on an end-to-end rotary shaker at $200 \mathrm{rpm}$, exhibiting a $\mathrm{pH}$ of 4.5. The $\mathrm{O}$ horizon leachate was passed through a $2 \mathrm{~mm}$ sieve to remove coarse particulates and centrifuged at $20,000 \mathrm{~g}$ for $2 \mathrm{~h}$. The supernatant was vacuum filtered successively through $0.8,0.45$ and $0.22 \mu \mathrm{m}$ polyethersulfone filters.

The $\mathrm{O}$ horizon leachate total $\mathrm{Mn}, \mathrm{Fe}, \mathrm{Cu}, \mathrm{Zn}, \mathrm{Al}, \mathrm{Ca}$, $\mathrm{Mg}, \mathrm{K}$ and $\mathrm{Na}$ content was determined by ICP-OES (Thermo Elemental Intrepid II XSP Duo View, Waltham, MA, USA). Dissolved Fe(II) was measured by the 1,10-phenanthroline method [56], and $\mathrm{Mn}$ speciation was assessed qualitatively in a freeze-dried sample using XPS (Thermo scientific K-alpha ${ }^{+}$XPS, East Grinstead, United Kingdom). Total organic $\mathrm{C}$, total $\mathrm{C}$, and total $\mathrm{N}$ were measured using a TOC Analyzer (Elementar Americas Vario Mx CN, Mt. Laurel, NJ, USA).

Hydrous $\mathrm{Mn}$ oxide (poorly crystalline $\delta-\mathrm{MnO}_{2}$ ), a $\mathrm{Mn}(\mathrm{IV})$ oxide similar to biogenic Mn oxides [57], and goethite were synthesized by standard methods and maintained as concentrated suspensions [58-60]. Briefly, $\mathrm{HMO}$ was synthesized by drop wise addition of $0.15 \mathrm{M}$ $\mathrm{Mn}\left(\mathrm{NO}_{3}\right)_{2} \cdot 4 \mathrm{H}_{2} \mathrm{O}$ to a solution comprised of $0.1 \mathrm{M}$ $\mathrm{KMnO}_{4}$ and $0.2 \mathrm{M} \mathrm{NaOH}$. The resulting suspension was stirred overnight (at least $12 \mathrm{~h}$ ) to allow complete conproportionation of $\mathrm{Mn}(\mathrm{II})$ and $\mathrm{Mn}(\mathrm{VII})$ to $\mathrm{Mn}(\mathrm{IV})$, and the HMO was used for all experimentation within 3 weeks of synthesis [61]. Goethite was made by slow $(\sim 48 \mathrm{~h})$ oxidation of dissolved $\mathrm{FeCl}_{2}$ buffered to $\mathrm{pH} 7$ by $\mathrm{NaHCO}_{3}$. The identity and purity of the minerals were confirmed by XRD (Additional file 1: Figure S1). The specific surface area of the minerals was determined by the BET equation applied to $\mathrm{N}_{2}$ adsorption data acquired at $77 \mathrm{~K}$ for relative pressures of 0.05 to 0.3 with a Micromeritics ASAP 2020 surface area analyzer (Norcross, GA, USA) [62, 63].
Particle size and electrophoretic mobility were measured simultaneously in deionized water by dynamic light scattering (Wyatt Technologies Möbiuל, Santa Barbara, CA), resulting in a calculation of zeta potential using the DYNAMICS software package (Wyatt Technologies). The point of zero charge (PZC) for HMO and goethite used in this study is 1.9 and 8.0, respectively [15, 64].

\section{Sorption experiment}

Sorption of DOM (from the O horizon leachate) onto $\mathrm{HMO}$ and goethite was performed at $22{ }^{\circ} \mathrm{C}$ over initial molar $\mathrm{C}$ :( $\mathrm{Mn}$ or $\mathrm{Fe})$ ratios of $0.2-9$ by reacting $45 \mathrm{mg}$ (dry weight equivalent) of mineral ( $\mathrm{HMO} /$ goethite) suspensions with $45 \mathrm{ml}$ of leachate solution of DOC varying concentration, yielding a solid:solution ratio of $\sim$ 1:1000 g dry wt $\mathrm{mL}^{-1}$. The initial C:(Mn or Fe) molar ratios are derived from the DOC concentration of the leachate-equivalent to the total $\mathrm{C}$ concentration within error-and the initial solid-phase $\mathrm{Mn}$ or Fe concentration. The $\mathrm{pH}$ of the suspensions was maintained at $5.0 \pm 0.2$ by addition of $\mathrm{HCl}$ or $\mathrm{NaOH}$. The total volume of $\mathrm{HCl}$ and/or $\mathrm{NaOH}$ required to achieve and maintain a $\mathrm{pH}$ of $5.0 \pm 0.2$ was $\leq 1 \%$ of the total initial suspension volume. The suspensions were shaken in the dark on an end-to-end rotary shaker at $150 \mathrm{rpm}$ for $24 \mathrm{~h}$, which was adequate time for steady state to be achieved (Additional file 1: Figure S2). Subsequently, the suspensions were centrifuged at 20,000 $g$ for $30 \mathrm{~min}$. The settled material was washed twice with DI water to remove the remainder of the equilibrium solution before freeze-drying [63]. Total $\mathrm{C}$ of the freeze-dried mineral-DOM complexes was measured using a vario Micro cube CHNS Analyzer (Elementar Analysensysteme $\mathrm{GmbH}$, Langenselbold, Germany).

\section{Desorption experiment}

Desorption of DOM from the sorption complexes was performed by reacting the moist solid-phase products with $10 \mathrm{~mL}$ of fresh $0.1 \mathrm{M} \mathrm{NaH}_{2} \mathrm{PO}_{4}(\mathrm{pH} 4.5)$ for two sequential $24 \mathrm{~h}$ periods as described previously [63], with one modification of increased shaking speed to $150 \mathrm{rpm}$. The centrifuged $(20,000 g)$ supernatants from the two extraction steps were combined and filtered with a $0.45 \mu \mathrm{m}$ filter and acidified to $1 \% \mathrm{HCl}$ (trace metal grade) for total $\mathrm{Mn}$ or Fe analysis by microwave plasma-atomic emission spectroscopy (Agilent Technologies 4100 MPAES, Santa Clara, CA).

\section{Biodegradation of non-sorbed DOM}

Biofilm reactors colonized and sustained by a continual perfusion with White Clay Creek stream water containing DOM and suspended bacteria were used to measure the aerobically biodegradable dissolved organic carbon 
(BDOC) content of leaf litter leachates as described previously [65]. White Clay Creek is the stream adjacent to the site where the composite $\mathrm{O}$ horizon sample was collected to prepare leachate that was then reacted with $\mathrm{HMO}$ and goethite at an initial $\mathrm{C}$ :( $\mathrm{Mn}$ or $\mathrm{Fe})$ molar ratio of 3.1. The BDOC of pre- and post-reaction leachates were measured. Details of the bioreactor design and methods for determining BDOC are provided in the Supplementary Material.

\section{X-ray photoelectron spectroscopy}

The XPS measurements were taken at the University of Delaware's Surface Analysis Facility (SAF) using a Thermo scientific K-alpha ${ }^{+}$XPS (East Grinstead, United Kingdom). Monochromatic aluminum K-alpha x-rays where used with a spot size of $100 \mu \mathrm{m}$, the flood gun was used to limit charging effects. Each sample had a survey spectrum taken with a $100 \mathrm{eV}$ pass energy and $1 \mathrm{eV}$ step. High-resolution scans were performed for every element found in any sample with atomic percent greater than $0.1 \%$, and the pass energy and step size used were $20 \mathrm{eV}$ and $0.1 \mathrm{eV}$, respectively. The powder samples where mounted on carbon tape with care to limit contamination. The pressed powders were hundreds of $\mu \mathrm{m}$ thick and the photoelectron escape depth is in the $\mathrm{nm}$ scale [66], and therefore the carbon tape did not contribute to any of the XPS spectra. To determine sample homogeneity and reproducibility, duplicate measurements where taken on each sample, and the results show that for elements found with greater than 2 atomic percent the signal variance was $1.5 \%$-well within the accepted range of $5 \%$ [67].

All peak processing was done in CasaXPS version 2.3.16. The following $\mathrm{C}$ types were distinguished: $\mathrm{C}$ bonded to $\mathrm{C}$ or $\mathrm{H}(\mathrm{C}-\mathrm{C}, \mathrm{C}=\mathrm{C}, \mathrm{C}-\mathrm{H}$; at $284.6 \mathrm{eV}), \mathrm{C}$ singly bonded to $\mathrm{O}$ or $\mathrm{N}(\mathrm{C}-\mathrm{O}, \mathrm{C}-\mathrm{N}$; at $286.1 \mathrm{eV})$, and $\mathrm{C}$ with multiple bonds to $\mathrm{O}(\mathrm{C}=\mathrm{O}, \mathrm{O}-\mathrm{C}-\mathrm{O}$; at $288.0 \mathrm{eV})$ similar to previous XPS analysis on DOM $[68,69]$. The carbon spectra were fit with a Shirley background and due to the amount of organic and inorganic material, 70-30 Gaussian-Lorentzian mix peaks were used with no constraints on peak position or peak broadness (Additional file 1: Figure S3). All full width half max values did not vary between species or sample by more than $0.2 \mathrm{eV}$, and the peak position did not vary by more than $0.2 \mathrm{eV}$. Manganese (Mn 2p 3/2) and Fe 2p 3/2 spectra were fit in a similar way to [70] with the position and width of the peaks constrained to the $\mathrm{Mn}(\mathrm{IV}), \mathrm{Mn}(\mathrm{III}), \mathrm{Mn}(\mathrm{II}), \mathrm{Fe}(\mathrm{III})$, and Fe(II) standards. Standards used for Mn and Fe XPS fitting were $\mathrm{Mn}(\mathrm{II})$ oxide (Sigma-Aldrich, CAS Number: 1344-43-0), Mn(III) oxide (Sigma-Aldrich, CAS Number: 1317-34-6), Mn(IV) oxide (Sigma-Aldrich, CAS Number: 1313-13-9), Fe(III) oxide (Sigma-Aldrich, CAS Number:
1309-37-1), and $\mathrm{Fe}(\mathrm{II}) \mathrm{Cl}_{2}$ (Sigma-Aldrich, CAS Number: 13478-10-9).

\section{Attenuated total reflectance-Fourier transform infrared spectroscopy}

The ATR-FTIR spectra were collected with a Bruker Tensor 27 FTIR spectrometer (Billerica, MA, USA) using the standard Pike ATR cell. Samples were freezedried and scanned over a range of $4000-600 \mathrm{~cm}^{-1}$ with a $2 \mathrm{~cm}^{-1}$ resolution. An average spectrum was obtained from 128 scans for each sample with the OPUS Data Collection Program (Version 7.2) (Bruker Corporation), and baseline subtraction was performed with GRAMS/ AI Spectroscopy Software (Version 9.2) (Thermo Fisher Scientific, Inc.). To obtain a spectrum of DOM associated with HMO or goethite, the baseline-corrected spectrum of pure HMO or pure goethite was subtracted from the spectrum of the DOM-HMO or DOM-goethite complex, respectively. Spectra were not normalized as all DOM peaks were impacted by the sorption reaction. Therefore, comparisons between ATR-FTIR spectra were limited to peak position and relative ratios of peak intensities.

\section{Scanning transmission X-ray microscopy}

In order to examine the spatial distribution and speciation of DOM sorbed onto HMO and goethite, STXMNEXAFS was performed at the C K-edge, $\mathrm{N}$ K-edge, metal ( $\mathrm{Mn}$ or $\mathrm{Fe}$ ) L-edge on DOM-HMO and DOMgoethite sorption complexes at beamline 10ID-1 at the Canadian Light Source as described previously for DOM-ferrihydrite complexes [63]. The DOM-HMO and DOM-goethite complexes were analyzed at two $C$ loadings each: $128 \pm 3.1 \mu \mathrm{g} \mathrm{m}^{-2}$ ("low") and $428 \pm 29 \mu \mathrm{g} \mathrm{m}^{-2}$ ("high") for HMO and $207 \pm 0.4 \mu \mathrm{g} \mathrm{m}^{-2}$ ("low") and $406 \pm 6.9 \mu \mathrm{g} \mathrm{m}^{-2}$ ("high") for goethite. The elemental detection limit for STXM-NEXAFS was 0.1\% [71]. The aXis2000 software package was used for image and spectra processing [72]. Linear combination fitting of $\mathrm{Mn}$ L-edge STXM-NEXAFS spectra was optimized over a range of 635-660 eV using four reference spectra of $\mathrm{Mn}$ oxide standards of varying oxidation state [73]. Linear combination of Fe L-edge STXM-NEXAFS spectra was optimized over a range of $700-730 \mathrm{eV}$ using $\mathrm{FeO}$ and $\mathrm{Fe}_{2} \mathrm{O}_{3}$ reference spectra from the authors' own database. A $1 \mathrm{~nm}$ thick elemental X-ray absorption profile was calculated with known chemical composition and density for each reference compound; each reference spectrum was scaled to its elemental X-ray absorption profile to obtain a reference spectrum of $1 \mathrm{~nm}$ thickness, which was used for the linear combination fitting [74]. The contribution of each standard to the linear combination fit 
(in $\mathrm{nm}$ ) was converted to a weight $\%$ using the standard's density.

\section{Results}

Mineral and $\mathrm{O}$ horizon leachate characterization

Hydrous Mn oxide is less crystalline than goethite and has two characteristic peaks at $37^{\circ}$ and $66^{\circ} 2 \theta(\mathrm{Cu} \mathrm{K \alpha})$ (Additional file 1: Figure S1) [75]. The $\mathrm{N}_{2}$-BET specific surface area (SSA) values obtained for the HMO and goethite are virtually equivalent $-138.0 \pm 1.3 \mathrm{~m}^{2} \mathrm{~g}^{-1}$ and $140.0 \pm 1.8 \mathrm{~m}^{2} \mathrm{~g}^{-1}$, respectively-and are comparable to those found elsewhere (Table 1) $[15,57,76]$. The mean particle diameter is in the sub-micron range and has a unimodal distribution for both HMO and goethite. The O horizon leachate has a wider particle size distribution, and shows evidence of flocculation in solution after filtration, as the mean particle diameter is greater than $0.2 \mu \mathrm{m}$ (Table 1). Hydrous Mn oxide and $\mathrm{O}$ horizon leachate are both negatively charged, whereas goethite is positively charged (Table 1).

The leachate has a $\mathrm{pH}$ of 4.5 and electrical conductivity of $0.156 \mathrm{~S} \mathrm{~m}^{-1}$ (Table 2). The C:N molar ratio is 10.5 , and previous characterization of the leachate from the site showed that $36 \%$ of the total $\mathrm{N}$ is present at $\mathrm{NH}_{4}{ }^{+}$and $0.05 \%$ is present as $\mathrm{NO}_{3}{ }^{-}$(data not shown). Dissolved $\mathrm{Mn}$ in the leachate is predominantly $\mathrm{Mn}$ (II) (Additional file 1: Figure S4), and $\sim 40 \%$ of the aqueous Fe is present as Fe(II) (data not shown), suggesting a substantial presence of complexed $\mathrm{Fe}(\mathrm{III})$ in solution. The dissolved $\mathrm{Mn}: \mathrm{Fe}$ molar ratio is 13.1 in the leachate. In deciduous (e.g. maple) foliage, Mn:Fe molar ratios may range from 7.2 to 100 [77]. The O horizon leachate contains a high Ca level $(2.5 \mathrm{mM})$, which may promote DOM sorption to metal oxides $[78,79]$.

\section{Organic C speciation of DOM and DOM-mineral complexes}

The C 1s XPS spectrum of the initial (unreacted) DOM contains 3 main $\mathrm{C}$ peaks: the most reduced $(\mathrm{C}-\mathrm{C}) \mathrm{C}$ peak, which includes reduced moieties, as well the adventitious $\mathrm{C}$ adsorbed from the air $[80,81]$, the $\mathrm{C}-\mathrm{O} / \mathrm{C}-\mathrm{N}$ peak chiefly indicative of polysaccharides and/or amino acids $[68,69,82]$ and the oxidized $(\mathrm{C}=\mathrm{O}) \mathrm{C}$ peak (Figs. 1,
2). The unreacted HMO shows evidence of primarily adventitious $\mathrm{C}$ (Fig. 1a), and the goethite contains adventitious $\mathrm{C}$ as well as a small oxidized $\mathrm{C}$ peak likely from residual oxidized carbon associated with the goethite synthesis procedure (Fig. 2a). All three $\mathrm{C}$ peaks in the unreacted DOM are present in the C 1s XPS spectra of the DOM-HMO and DOM-goethite complexes. Increasing $\mathrm{C}$ loading on $\mathrm{HMO}$ and goethite shows a decrease and subsequent stabilization in the percent carbon signal of reduced $(\mathrm{C}-\mathrm{C}) \mathrm{C}$, and an increase and subsequent leveling off of the percent carbon signal of both the polysaccharide/amino acid-associated $\mathrm{C}(\mathrm{C}-\mathrm{O}$ and $\mathrm{C}-\mathrm{N})$ and the oxidized $(\mathrm{C}=\mathrm{O}) \mathrm{C}$ (Figs. 1c and 2c).

The C NEXAFS spectrum of the unreacted DOM has three main peaks: an aromatic $\left(\pi^{*} \mathrm{C}=\mathrm{C}\right)$ peak at $285.1 \mathrm{eV}$, a phenolic $\left(\pi^{*} \mathrm{C}=\mathrm{C}-\mathrm{O}\right)$ peak at $286.5 \mathrm{eV}$, and a prominent carboxylic $\left(\pi^{*} \mathrm{C}=\mathrm{O}\right)$ peak at $288.4 \mathrm{eV}$ as obtained previously (Fig. 3) [63]. Sorption of the DOM onto the HMO and goethite results in a dampening of the aromatic $\mathrm{C}$ peak and a disappearance of the phenolic $C$ peak with the carboxylic peak remaining pronounced (Fig. 3). Increasing $\mathrm{C}$ loading onto the $\mathrm{HMO}$ and goethite results in an increase in the carboxylic $C$ peak intensity.

The ATR-FTIR spectrum of the unreacted DOM shows predominant peaks at 1583 and $1404 \mathrm{~cm}^{-1}$ indicative of an asymmetric $\mathrm{COO}^{-}$stretch and symmetric $\mathrm{COO}^{-}$ stretch, respectively, as well as a peak at $1043 \mathrm{~cm}^{-1}$ representing a $\mathrm{C}-\mathrm{O}$ stretch of polysaccharides (Fig. 4; Additional file 1: Table S1). Sorption of DOM onto goethite shifts the asymmetric $\mathrm{COO}^{-}$peak from 1583 to $1591 \mathrm{~cm}^{-1}$ and shifts the symmetric $\mathrm{COO}^{-}$peak from 1404 to $1390 \mathrm{~cm}^{-1}$-indicative of carboxylate-metal bond formation - and decreases the symmetric $\mathrm{COO}^{-}$ peak/C-O stretch of polysaccharides (at $\sim 1042 \mathrm{~cm}^{-1}$ ) ratio from 1.27 to 1.18 (Fig. 4). Sorption of DOM onto $\mathrm{HMO}$ does not shift the asymmetric $\mathrm{COO}^{-}$peak (providing no indication of carboxylate-metal bond formation), shifts the symmetric $\mathrm{COO}^{-}$peak from 1404 to $1414 \mathrm{~cm}^{-1}$, shifts the predominant $\mathrm{C}-\mathrm{O}$ stretch of polysaccharides from 1043 to $1051 \mathrm{~cm}^{-1}$, and decreases the symmetric $\mathrm{COO}^{-}$peak/C-O stretch of polysaccharides ratio from 1.27 to 0.95 (Fig. 4).

Table 1 Characterization of hydrous Mn oxide, goethite, and leaf litter leachate (pH 4.5)

\begin{tabular}{lllll}
\hline Material & Specific surface area $\left(\mathbf{m}^{\mathbf{2}} \mathbf{g}\right)$ & Mean particle diameter $(\mathbf{n m})$ & Zeta potential $(\mathbf{m V})$ & $\begin{array}{l}\text { Electrophoretic mobility } \\
\left(\boldsymbol{\mu m} / \mathbf{s}[\mathbf{V} / \mathbf{c m}]^{-\mathbf{1}}\right)\end{array}$ \\
\hline Hydrous Mn oxide & $138 \pm 1.3$ & $309 \pm 16$ & $-502 \pm 46$ & $-502 \pm 46$ \\
Goethite & $140 \pm 1.8$ & $661 \pm 81$ & $+284 \pm 36$ & $+284 \pm 36$ \\
Dissolved NOM & N/A & $429 \pm 170$ & $-223 \pm 68$ & $-223 \pm 68$ \\
\hline
\end{tabular}

Error bars indicate standard deviation of mean for triplicate measurements 


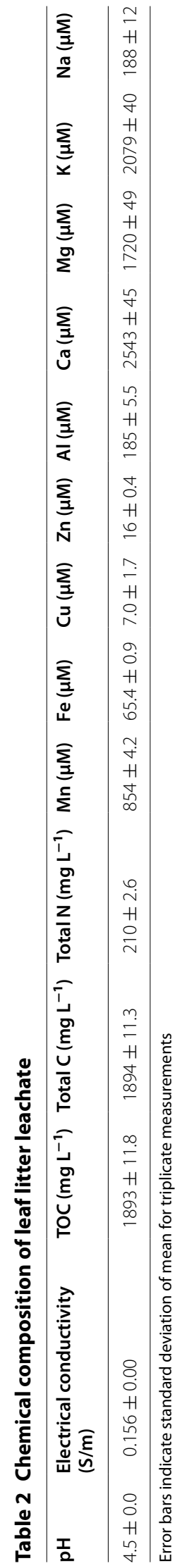




\section{a}
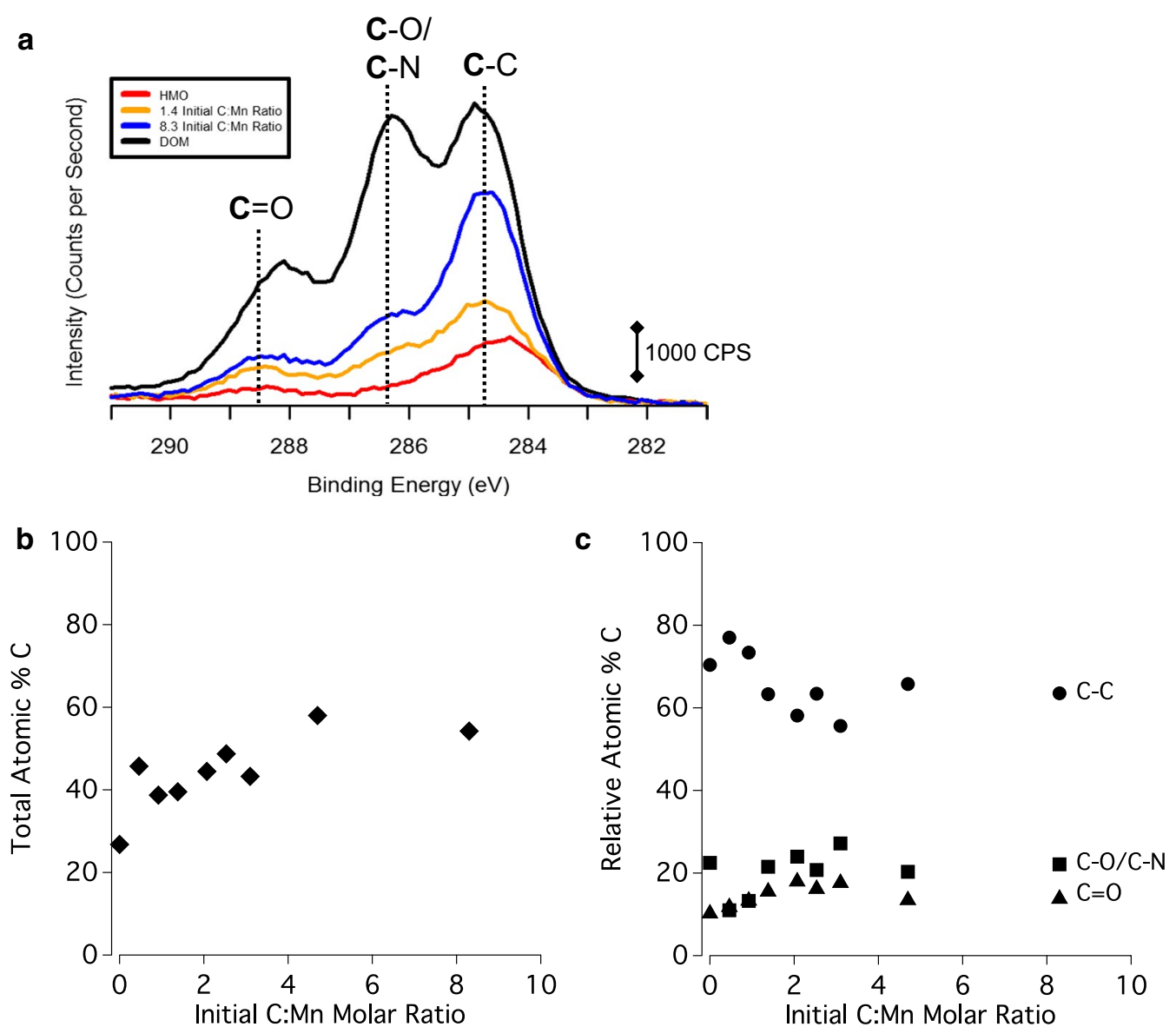

Fig. 1 a XPS of the C 1s region of the DOM shown in black, 8.3 initial C:Mn molar ratio samples in blue, 1.4 initial C:Mn molar ratio sample in yellow, and untreated $\mathrm{HMO}$ shown in red. The region is broken into three distinct species: the most oxidized is the $\mathrm{C}$ that is double bonded to $\mathrm{O}$ labeled as $\mathrm{C}=\mathrm{O}$ at $288.2 \mathrm{eV}$, the middle species is labeled as $\mathrm{C}-\mathrm{O}$ and $\mathrm{C}-\mathrm{N}$ at $286.1 \mathrm{eV}$, and the least oxidized carbon is the $\mathrm{C}-\mathrm{C}$ or $\mathrm{C}-\mathrm{H}$ carbon at $284.6 \mathrm{eV}$. b The $\mathrm{C}$ atomic percent of each sample based on every element detected with XPS. cThe most reduced $\mathrm{C}$ species, the $\mathrm{C}-\mathrm{O}$ and $\mathrm{C}-\mathrm{N}$ associated $\mathrm{C}$, and the most oxidized $C(C=O)$, each expressed by relative atomic percent of the total $C$ signal as a function of the initial $C: M n$ molar ratio

\section{Nanoscale spatial distribution of DOM on HMO and goethite}

Heterogeneity of $\mathrm{C}$ distribution decreases with increasing $\mathrm{C}$ loading on the HMO (Fig. 5). Carbon hotspots occur at the low $\mathrm{C}$ loading, and $\mathrm{C}$ is more homogenously distributed at the high $\mathrm{C}$ loading. No distinct $\mathrm{C}$ phases are observed irrespective of $\mathrm{C}$ loading on the HMO. Nitrogen is homogeneously distributed at both low and high C loadings.

Carbon hotspots occur at both low and high $\mathrm{C}$ loadings on the goethite, but $\mathrm{C}$ is more homogeneously distributed at the high $C$ loading (Fig. 5). No distinct $C$ phases are observed irrespective of $C$ loading on the goethite. Nitrogen is homogeneously distributed at both low and high $\mathrm{C}$ loadings.

\section{Sorption of DOM and quantifying mineral dissolution}

Goethite shows a sharp increase in sorption of organic $\mathrm{C}$ up to $388 \mu \mathrm{g} \mathrm{C} \mathrm{m}^{-2}$ for low $(\sim<1)$ initial C:Fe molar ratios, with slight increases in organic $C$ sorption up to $478 \mu \mathrm{g} \mathrm{C} \mathrm{m}^{-2}$ for higher initial C:Fe molar ratios (Fig. 6). Hydrous Mn oxide has a lower affinity for organic $\mathrm{C}$ at low $(\sim<)$ initial C:Mn molar ratios, but has a higher $\mathrm{C}$ sorption capacity at higher initial C:Mn molar ratios, retaining $635 \mu \mathrm{g} \mathrm{C} \mathrm{m}^{-2}$ for an initial C:Mn molar ratio of 9. The increase in total atomic percent $C$ as detected by $\mathrm{C} 1 \mathrm{~s}$ XPS as a function of initial C:metal molar ratio corroborates the $\mathrm{C}$ sorption trend observed using the $\mathrm{CHNS}$ analyzer (Figs. 1b, 2b, 6).

Reaction of HMO and goethite with DI water for $24 \mathrm{~h}$ results in $3.7 \mu \mathrm{M}$ Mn and $9.1 \mu \mathrm{M}$ Fe in solution, respectively (Additional file 1: Figure S5; Initial C:(Mn or Fe) ratio $=0$ ), indicating negligible mineral dissolution or metal desorption from the solid phase. However, HMO 


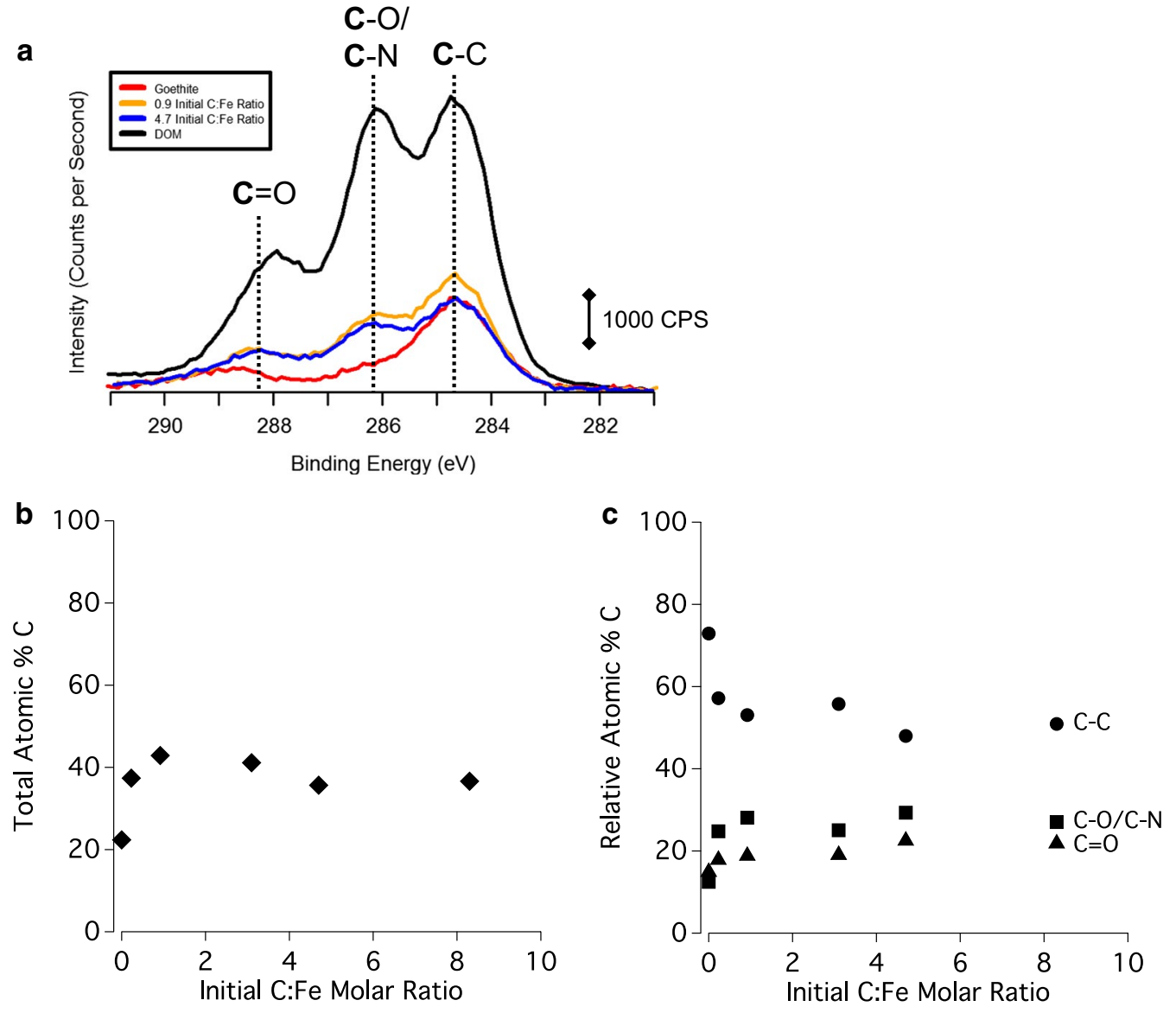

Fig. 2 a XPS of the C 1s region of the DOM shown in black, 4.7 initial C:Fe molar ratio samples in blue, 0.9 initial C:Fe molar ratio sample in yellow, and untreated goethite shown in red. The region is broken into three distinct species: the most oxidized is the $\mathrm{C}$ that is double bonded to $\mathrm{O}$ labeled as $\mathrm{C}=\mathrm{O}$ at $288.2 \mathrm{eV}$, the middle species is labeled as $\mathrm{C}-\mathrm{O}$ and $\mathrm{C}-\mathrm{N}$ at $286.1 \mathrm{eV}$, and the least oxidized carbon is the $\mathrm{C}-\mathrm{C}$ or $\mathrm{C}-\mathrm{H}$ carbon at $284.6 \mathrm{eV}$. b The $C$ atomic percent of each sample based on every element detected with XPS. c The most reduced $C$ species, the $C-O$ and $C-N$ associated $C$, and the most oxidized $\mathrm{C}(\mathrm{C}=\mathrm{O})$, each expressed by relative atomic percent of the total $\mathrm{C}$ signal as a function of the initial C:Mn molar ratio

and goethite show differential stability upon reaction with the $\mathrm{O}$ horizon leachate. The HMO batch system shows increasing Mn release into solution-and HMO dissolution-with increasing initial C:Mn molar ratio (Additional file 1: Figure S5). The net change in dissolved $\mathrm{Mn}$ in the goethite system, as well as in the dissolved Fe in both the HMO and goethite systems is negative, indicating a net re-partitioning of dissolved metals to the solid phase upon reaction with the $\mathrm{O}$ horizon leachate. Thus, contrary to HMO, no leachate-induced dissolution of goethite is observed.

The electrical conductivity of the leachate solutions reacted with $\mathrm{HMO}$ and goethite ranges from $5.7 \times 10^{-3}$ to $1.5 \times 10^{-1} \mathrm{~S} \mathrm{~m}^{-1}$. Adopting a pseudo-linear relationship between electrical conductivity and ionic strength [83], the ionic strength of the leachate solutions ranges from approximately $0.8-24 \mathrm{mM}$. Ionic strength variance has negligible impact on the adsorption of DOM onto mineral oxide surfaces for freshwater solutions with an ionic strength less than $100 \mathrm{mM}$ [84].

\section{Manganese reduction of $\mathrm{HMO}$ by $\mathrm{O}$ horizon leachate}

Scanning transmission X-ray microscopy-Mn L-edge NEXAFS shows that the unreacted HMO is predominantly in the form of $\mathrm{Mn}(\mathrm{IV})$ in accordance with other studies (Fig. 7a) [57, 61]. Reaction of HMO with increasing $\mathrm{O}$ horizon leachate concentration results in increasing $\mathrm{Mn}$ reduction of the HMO (Fig. 7a). For instance, as initial C:Mn molar ratio increases from 0.46 to 2.5 , the proportion of $\mathrm{MnO}_{2}$ in the resulting DOM-HMO complex decreases from $64 \%(\mathrm{w} / \mathrm{w})$ to $10 \%(\mathrm{w} / \mathrm{w})$, whereas the proportion of $\mathrm{Mn}(\mathrm{II} / \mathrm{III})$ oxides increases from $36 \%$ $(\mathrm{w} / \mathrm{w})$ to $90 \%(\mathrm{w} / \mathrm{w})$ (Additional file 1: Table S2). Congruently, Mn XPS shows an increasing proportion of Mn(II) 


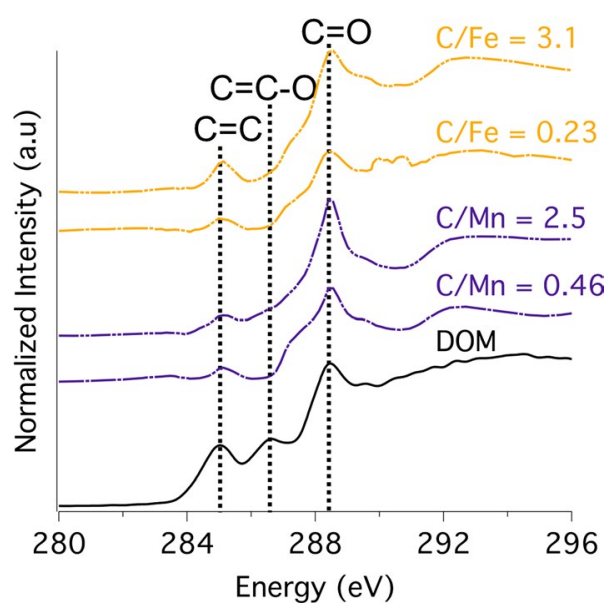

Fig. 3 Carbon 1s NEXAFS spectra collected at a synchrotron-based scanning transmission X-ray microprobe for the unreacted DOM, $\mathrm{HMO}$ with initial C:Mn molar ratios of 0.46 and 2.5 , and goethite with initial C:Fe molar ratios of 0.23 and 3.1. The aromatic $(C=C)$, phenolic $(C=C-O)$, and carboxylic $(C=O) C$ peaks locations are shown for reference

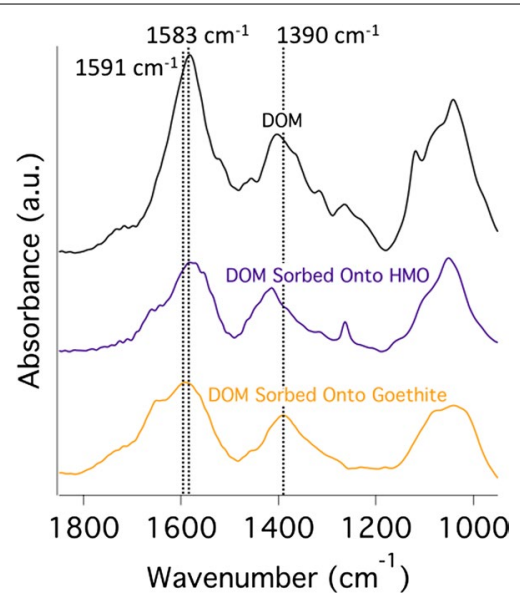

Fig. 4 ATR-FTIR spectra of DOM-HMO and DOM-goethite sorption complexes in comparison with that of the unreacted DOM. The DOM-HMO and DOM-goethite sorption complexes result from initial C:metal molar ratios of 3.1 and have comparable $\mathrm{C}$ loadings (59.6 $\pm 7.1 \mathrm{mg} \mathrm{C} \mathrm{g}^{-1}$ and $56.8 \pm 1.0 \mathrm{mg} \mathrm{C} \mathrm{g}^{-1}$, respectively)

with increasing $\mathrm{C}$ loading onto the HMO (Fig. 8d). For instance, as initial C:Mn molar ratio increases from 0.46 to 8.3 , the percent of the total Mn present as $\mathrm{Mn}$ (II) increases from 23 to $54 \%$ (Fig. 8d). An increase in the $\mathrm{Mn}(\mathrm{II})$ concentration in the DOM-HMO sorption complexes is strongly correlated with an increase in the oxidized $(\mathrm{C}=\mathrm{O}) \mathrm{C}$ atomic $\%(\mathrm{r}=0.78, \mathrm{P}<0.0006)$ (Additional file 1: Table S3).

On the other hand, sorption of DOM onto goethite induces a relatively low extent of $\mathrm{Fe}(\mathrm{III})$ reduction in the
STXM-Fe L-edge NEXAFS spectra (Fig. 7b). For instance, as initial C:Fe molar ratio increases from 0.23 to 3.1, the proportion of $\mathrm{FeO}$ in the resulting $\mathrm{DOM}$-goethite complex increases from $10 \%(\mathrm{w} / \mathrm{w})$ to $18 \%(\mathrm{w} / \mathrm{w})$ (Additional file 1: Table S4). According to Fe XPS, a surface-sensitive technique, Fe(II) is below quantifiable detection in the DOM-goethite complexes (Fig. 9).

\section{Desorption of DOM}

Oxyanions (e.g., $\mathrm{H}_{2} \mathrm{PO}_{4}{ }^{-}$and $\mathrm{SO}_{4}{ }^{2-}$ ) are known to compete with DOM for binding sites on metal oxide surfaces, resulting in DOM release to solution $[85,86]$. For instance, $\mathrm{H}_{2} \mathrm{PO}_{4}^{-}$forms strong bonds on metal oxide surfaces via surface complexation [87]. Total $\mathrm{P}$ and total $\mathrm{S}$ are $\sim 0.6$ and $0.4 \%$ of the total $\mathrm{C}$ in the $\mathrm{O}$ horizon leachate on a molar basis (data not shown), respectively, and therefore $\mathrm{H}_{2} \mathrm{PO}_{4}{ }^{-}$and $\mathrm{SO}_{4}{ }^{2-}$ most probably provide minimal competition with DOM for sorption sites in this batch system. However, adding $\mathrm{H}_{2} \mathrm{PO}_{4}{ }^{-}$in excess-in the form of a $0.1 \mathrm{M} \mathrm{NaH}_{2} \mathrm{PO}_{4}$ extraction-may serve as an estimate for the amount of DOM capable of being desorbed through ligand exchange [15]. At a low $\left(1.9 \times 10^{2}-\right.$

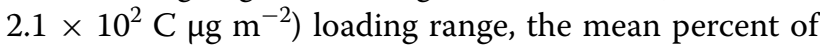
$\mathrm{C}$ desorbed from $\mathrm{HMO}$ and goethite by extraction with $0.1 \mathrm{M} \mathrm{NaH}_{2} \mathrm{PO}_{4}$ is $25 \pm 16 \%(\mathrm{w} / \mathrm{w})$ and $57 \pm 4 \%$, respectively (Fig. 1). At higher $\mathrm{C}$ loadings, the mean percent of $\mathrm{C}$ desorbed increases in the HMO system, ranging from $69 \pm 15$ to $74 \pm 13 \%$, and remains roughly constant relative to the lower $\mathrm{C}$ loading in the goethite system, ranging from $48 \pm 7$ to $67 \pm 2 \%$ (Fig. 1).

Reaction with $0.1 \mathrm{M} \mathrm{NaH}_{2} \mathrm{PO}_{4}$ results in release of 2.5-2.8\% (mol-basis) of the initial solid-phase $\mathrm{Mn}$ of HMO into the aqueous phase and $0.1-0.2 \%$ (mol-basis) of the initial solid-phase Fe of goethite into the aqueous phase (Additional file 1: Figure S6). The high release of desorbed Mn from HMO is attributable to O horizon leachate-induced dissolution of HMO and $\mathrm{Mn}$ introduced with the $\mathrm{O}$ horizon leachate, whereas the low desorbed Fe levels in the goethite system are corroborative evidence for the lack of observed goethite dissolution. The $\mathrm{pH}$ of $0.1 \mathrm{M} \mathrm{NaH}_{2} \mathrm{PO}_{4}$ is 4.5 , and therefore and $\mathrm{Mn}$ or Fe released into solution should not result from acidityinduced dissolution of HMO and goethite, as the minerals are stable under even more acidic conditions [4, 57]. The $0.1 \mathrm{M} \mathrm{NaH}_{2} \mathrm{PO}_{4}$ extraction performed on the initial $\mathrm{HMO}$ and initial goethite resulted in $0.08 \%$ of the initial solid-phase Mn desorbed and $0.06 \%$ of the initial solid-phase Fe desorbed, respectively. Therefore, $0.1 \mathrm{M}$ $\mathrm{NaH}_{2} \mathrm{PO}_{4}$ does not contribute significantly to the mineral dissolution over and above what occurs upon reaction with the $\mathrm{O}$ horizon leachate. 

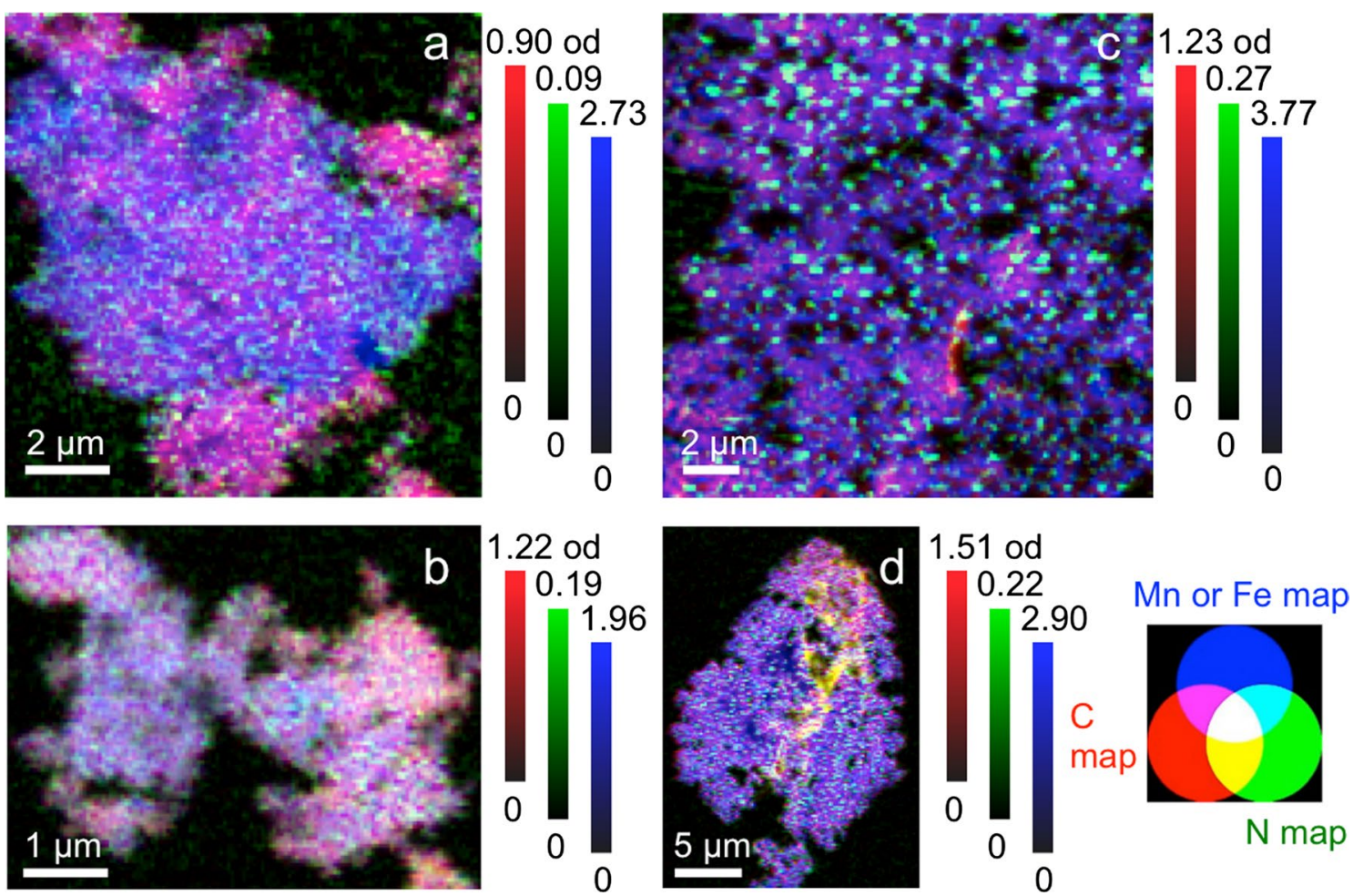

Fig. 5 Color-coded composite STXM maps of C (red), N (green), and metal (blue; Mn for HMO and Fe for goethite) for a HMO with initial C:Mn ratio of 0.46 , b HMO with initial C:Mn ratio of 2.5, $\mathbf{c}$ goethite with initial C:Fe ratio of 0.23 , and $\mathbf{d}$ goethite with initial C:Fe ratio of 3.1. Color bars are optical density ranges for each element in each specific sample

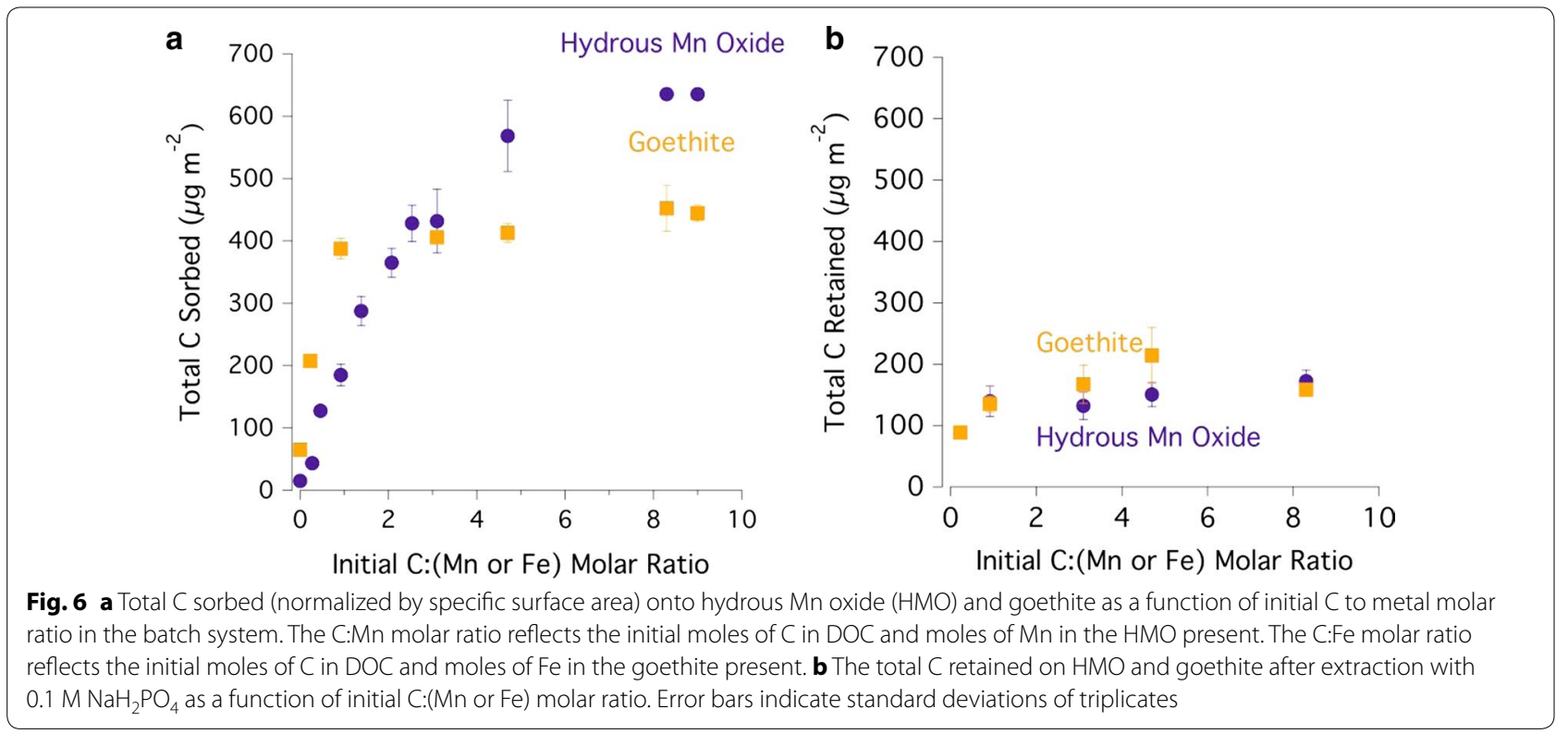

Mineral impacts on biodegradability of aqueous DOM The mean BDOC expressed as a percent of the total DOC in the White Clay Creek stream water was
$35 \pm 4.1 \%$ - prior to injection of the O horizon leachate samples (data not shown). The native microbial population of the White Clay Creek site are able to degrade 

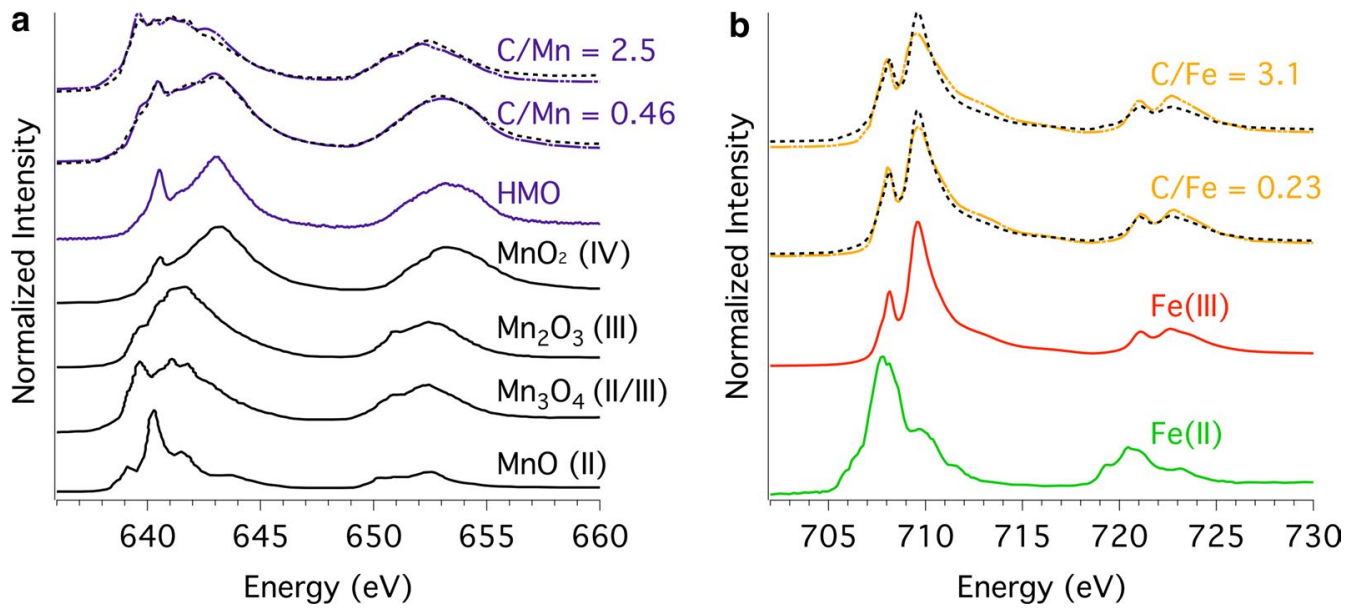

Fig. 7 a Scanning transmission X-ray microscopy-Mn L-edge NEXAFS spectra for the DOM-HMO complexes with initial C:Mn molar ratios of 0.46 and 2.5 (solid lines), as well as the linear combination fits (dashed lines). The unreacted HMO spectrum and reference spectra for Mn oxide standards from Gilbert, Frazer [73] are provided for comparison. b Scanning transmission X-ray microscopy-Fe L-edge NEXAFS spectra for goethite with initial C:Fe molar ratios of 0.23 and 3.1 Iron(II) and Fe(III) reference spectra are shown for comparison

90\% of the leachate DOC (Fig. 10), indicating a high biodegradability relative to the stream water DOC. Biodegradability of the leachate DOC is similar to the rates measured for a cold water extracted tulip poplar tree tissues, in which $>80 \%$ of the leachate was biodegradable both in the bioreactors and in a whole stream release [88]. Reaction with HMO or goethite at an initial C:(Mn or Fe) molar ratio of 3.1 did not statistically change the $\% \mathrm{BDOC}$ of the aqueous DOM according to our method.

\section{Discussion}

\section{Potential Mechanisms of DOM sorption to HMO and goethite}

Carboxylic, phenolic, aromatic $\mathrm{C}$, and polysaccharideassociated $\mathrm{C}$ groups comprise the principal $\mathrm{C}$ species types of the DOM in this study (Figs. 1, 2, 3, 4). Hydrous Mn oxide and goethite preferentially sorb carboxylic $\mathrm{C}$ over phenolic $\mathrm{C}$ and aromatic $\mathrm{C}$ (Fig. 3). The $\mathrm{C}-\mathrm{O}$ stretching of phenolic $\mathrm{OH}$ peak at $\sim 1265 \mathrm{~cm}^{-1}$ in the ATR-FTIR spectrum is maintained by HMO, but is absent in the case of goethite (Fig. 4). However, this peak is also in the range of $\mathrm{C}-\mathrm{O}$ stretching of polysaccharides (Additional file 1: Table S1), and therefore may not reflect sorption of phenolic C. HMO shows stronger sorption extent for polysaccharide-associated $\mathrm{C}$ relative to goethite with a lower symmetric $\mathrm{COO}^{-}$peak/C-O stretch of polysaccharides ratio in the ATR-FTIR spectrum (Fig. 4). Thus, polysaccharide moieties appear to play an important role in the extent and mechanism of DOM sorption by HMO, standing in contrast to findings for goethite [4, $13,89]$.
The shift in the asymmetric $\mathrm{COO}^{-}$peak from 1583 to $1591 \mathrm{~cm}^{-1}$ in the goethite-reacted DOM ATR-FTIR spectrum relative to the unreacted DOM spectrum and the associated appearance of the COO- metal stretch at $1390 \mathrm{~cm}^{-1}$ is evidence of partial carboxylate-metal bond formation through ligand exchange (Fig. 4), which is a well established DOM sorption mechanism for goethite $[4,13,19,85,86,90,91]$. Fourier transform infrared spectroscopy shows evidence for ligand exchange as the sorption mechanism between ferrihydrite and DOM collected from the same field site [63]. Ligand exchange is a particularly common interaction mechanism between carboxylic $\mathrm{OH}$ groups and metal oxide surfaces under acidic conditions, as the $\mathrm{pKa}$ values for most carboxylic acids in soils are between 4.3 and 4.7 [12, 85, 92]. Phenolic and aromatic $\mathrm{C}$ groups form complexes with metal oxides through ligand exchange under acid conditions as well [92, 93].

Reaction of goethite and $\mathrm{HMO}$ with the $\mathrm{O}$ horizon leachate resulted in consistent slight increases in $\mathrm{pH}$, especially during the first few hours of reaction (data not shown). Monitoring of $\mathrm{pH}$ and addition of $\mathrm{HCl}$ was required to maintain the $\mathrm{pH}$ at $5.0 \pm 0.2$. An increase in $\mathrm{pH}$ is evidence of a ligand exchange reaction between DOM functional groups and hydroxyl groups at metal oxide surfaces (e.g., goethite), especially for specific adsorption of anions of weak acids [15, 94]. Nevertheless, the symmetric $\mathrm{COO}^{-}$stretch peak of HMO-reacted DOM (difference spectrum between DOM sorbed onto HMO spectrum and the unreacted HMO spectrum) does not shift to the COO- metal stretch position at $\sim 1390 \mathrm{~cm}^{-1}$ (Fig. 4), which would be indicative of ligand 

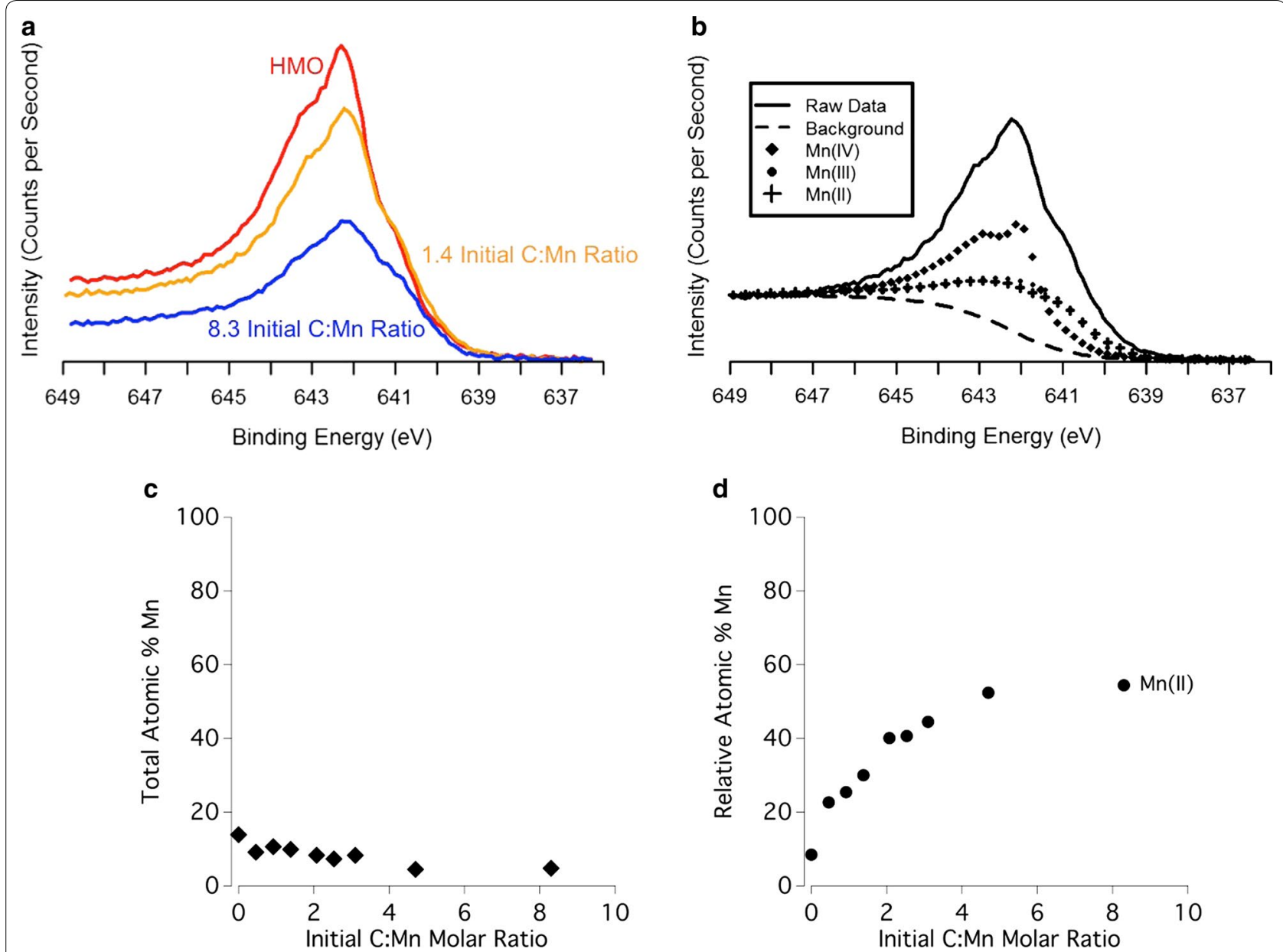

Fig. 8 a XPS of the Mn 2p 3/2 region of the 8.3 initial C:Mn molar ratio samples in blue, 1.4 initial C:Mn molar ratio sample in yellow, and untreated $\mathrm{HMO}$ shown in red. The region is broken into two distinct species; the one of lower binding energy located at $640.7 \mathrm{eV}$ is the Mn(II) peak, and the higher energy peak is a custom line shape of the untreated HMO. b The raw Mn XPS spectrum along with the background and Mn XPS standard spectra used for fitting. c The Mn atomic percent based on all of elements detected with XPS. $\mathbf{d}$ The increase in the \% of Mn present as Mn(II) as the samples were exposed to increasing amounts of DOM

exchange between the carboxylate and the HMO surface. The symmetric $\mathrm{COO}^{-}$stretch peak of the HMOreacted DOM actually increases to $1414 \mathrm{~cm}^{-1}$ (Fig. 4), which is still in the carboxylate range [95]. Similarly, birnessite-reacted DOM (difference spectrum between DOM sorbed and unreacted birnessite) shifts wavenumber position from 1400 to $1420 \mathrm{~cm}^{-1}$ relative to the unreacted DOM spectrum [13]. However, the FTIR spectrum of DOM supernatant solution reacted with birnessite shows a shift of the symmetric $\mathrm{COO}^{-}$stretch peak to the COO- metal stretch position of $1390 \mathrm{~cm}^{-1}$, consistent with the formation of Mn-carboxylate complexes in solution [13]. In this study, we did not measure ATR-FTIR spectra of DOM supernatant solutions post-reaction with HMO.
Apart from ligand exchange, another potential sorption mechanism between DOM and HMO is electrostatic interaction. However, electrostatic interaction between $\mathrm{DOM}$ and $\mathrm{HMO}$ is also unlikely at $\mathrm{pH} 5$, as the PZC of HMO is 1.9 , and therefore HMO surface sites should be predominantly negatively charged and electrostatically repel DOM, which also has a net negative charge [96]. Indeed, the zeta potential and electrophoretic mobility of both the unreacted DOM and unreacted HMO are negative (Table 1).

Weak interactions in various forms may contribute to sorption of DOM to HMO and goethite including physical adsorption due to favorable entropy changes, attraction of hydrophobic moieties at the exclusion of water, hydrogen bonding, and Van der Waals forces [12, 97]. 


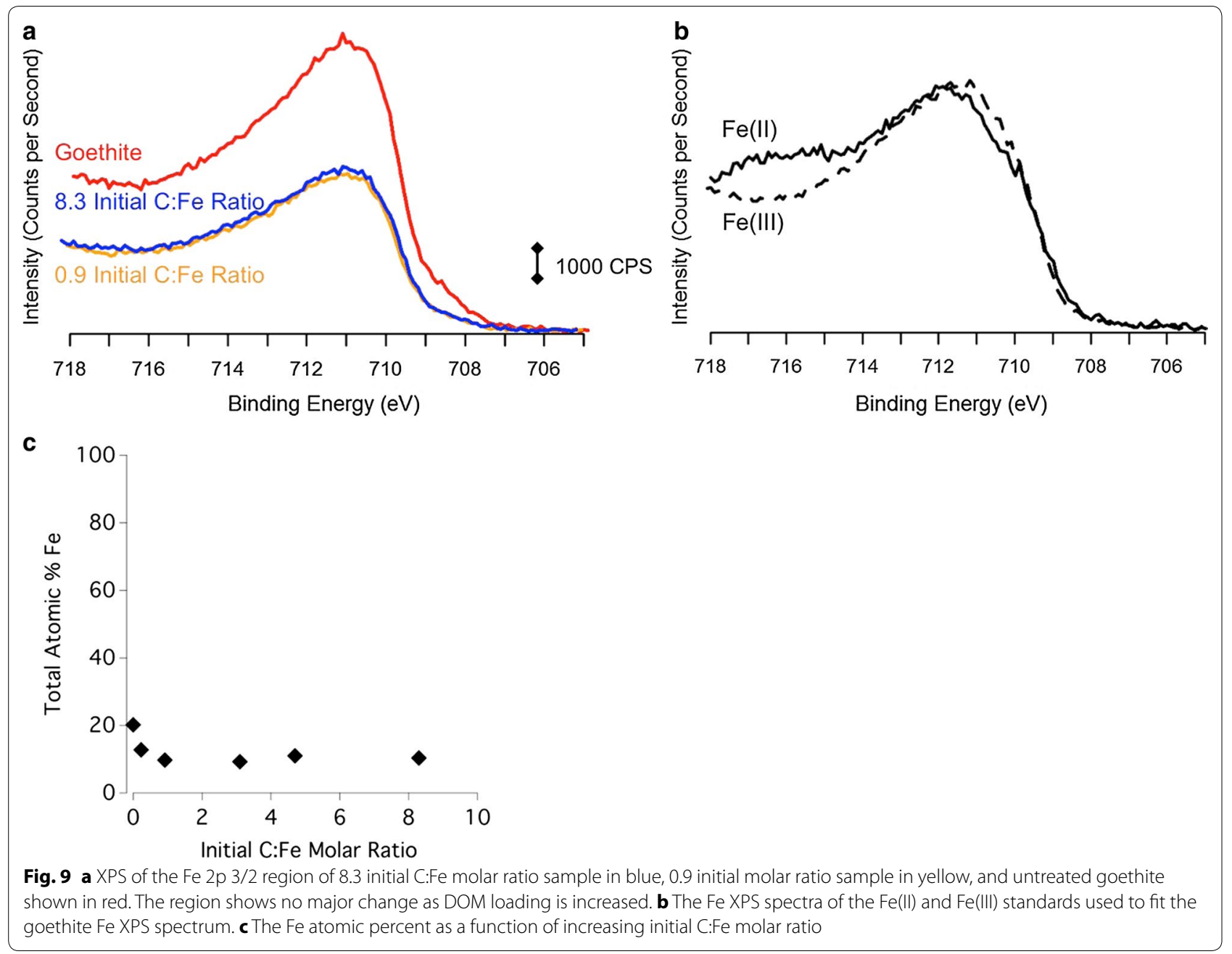

However, physical adsorption is unlikely where ligand exchange occurs between DOM and metal oxides [85], as in the case of goethite. Hydrophobic interactions may

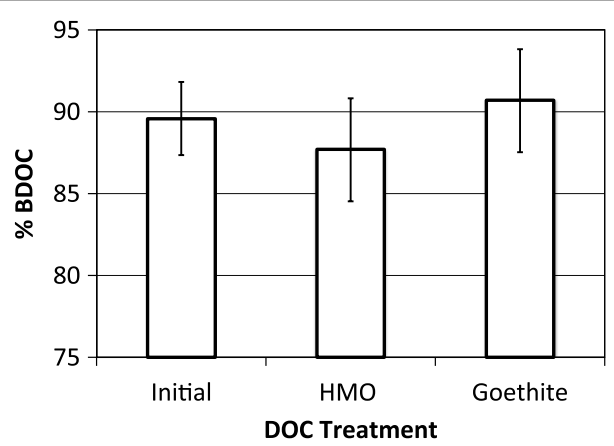

Fig. 10 Mean \% biologically degradable organic carbon (BDOC) of the initial (unreacted) dissolved DOM and the dissolved DOM after reaction with $\mathrm{HMO}$ and goethite at an initial $\mathrm{C}:(\mathrm{Mn}$ or $\mathrm{Fe})$ molar ratio of 3.1. Error bars indicated standard errors as calculated by the TukeyKramer HSD test occur at high DOM loadings, but are less likely where carboxylic functional groups predominate under acidic conditions [15], as in the case of the DOM in this study. The enhanced spatial correlation between $\mathrm{C}$ and $\mathrm{Mn}$ and between $\mathrm{C}$ and $\mathrm{Fe}$ with increasing $\mathrm{C}$ loading in DOMHMO and DOM-goethite complexes, respectively (Additional file 1: Figure S7), as well as the lack of discrete $C$ phases, does not support the agglomeration of hydrophobic $\mathrm{C}$ moieties (Fig. 5). Hydrogen bonding and Van der Waals forces cannot be excluded, but typically increase in sorption contribution for uncharged $\mathrm{C}$ moieties [12], which does not apply to the negatively charged DOM of the current study (Table 1). In sum, whereas ligand exchange with carboxylate groups is evidently the predominant DOM sorption mechanism for goethite, the DOM sorption mechanism on the HMO surface remains less defined, though carboxylates and polysaccharides appear to be involved (Figs. 1 and 4). 


\section{Potential mechanisms for $\mathrm{O}$ horizon leachate-induced $\mathrm{Mn}$ reduction of $\mathrm{HMO}$}

At low $\mathrm{C}$ loadings, DOM sorbed onto HMO has a greater percent carbon signal of reduced $(\mathrm{C}-\mathrm{C}) \mathrm{C}$ species compared to DOM-goethite complexes (Figs. 1, 2). Increasing $\mathrm{C}$ loading on $\mathrm{HMO}$ clearly shows a decrease in the percent carbon signal of reduced $(\mathrm{C}-\mathrm{C}) \mathrm{C}$ and a concomitant increase in more oxidized forms (i.e., $\mathrm{C}-\mathrm{O} / \mathrm{C}-$ $\mathrm{N}$ and $\mathrm{C}=\mathrm{O}$ ) (Fig. 1). The increase in $\mathrm{C}$ oxidation state of DOM induced by reaction with $\mathrm{HMO}$ is accompanied by a reduction of Mn (Figs. 7a and 8 ). Increasing $\mathrm{Mn}$ (II) production is most strongly correlated with an increase in oxidized $\mathrm{C}(\mathrm{C}=\mathrm{O})$ species sorbed to $\mathrm{HMO}$ (Additional file 1: Table S3), suggesting the potential for $C$ oxidation and/or selective sorption of oxidized $C$ species.

Dissolved organic matter may serve as a $\mathrm{Mn}$ oxide reductant through surface complexation [13, 98, 99], resulting in partial dissolution of $\mathrm{HMO}$, though the DOM specific functional groups that would be involved are not clear. On the other hand, DOM has a lower capacity to induce reduction of goethite (Figs. 7b and 9) similar to results of a previous study [13]. Dissolved organic matter induces $\mathrm{Mn}$ reduction of birnessite, a more crystalline $\delta-\mathrm{MnO}_{2}$ than $\mathrm{HMO}$, which also has a greater capacity to oxidize DOM than does goethite through more favorable energetics [13]. The oxidative capacity of birnessite is implicated as the reason for enhanced decomposition rates of noncellulosic polysaccharides in beech litter, whereas $\mathrm{Fe}$ and $\mathrm{Al}$ oxides decrease litter decomposition rates [23]. Birnessite increases the $\mathrm{C}$ oxidation state of lignin in beech litter to a greater extent than does akageneite $(\beta-\mathrm{FeOOH})[25]$. Whether or not the greater oxidative capacity of $\mathrm{Mn}$ oxides over $\mathrm{Fe}$ oxides translates into increased litter or DOM decomposition rates will depend on chemistry of the organic $\mathrm{C}$ substrate and the microbial community present among other factors [23-25].

In addition to DOM, dissolved $\mathrm{Mn}(\mathrm{II})$ from the O horizon leachate is a second potential Mn reductant responsible for the dissolution of HMO. The observed reduced Mn species on the solid phase are not exclusively sorbed $\mathrm{Mn}$ (II) from the $\mathrm{O}$ horizon leachate, as reduced $\mathrm{Mn}$ is accompanied by HMO dissolution (Additional file 1: Figure S5) and is detected by transmission-based STXMNEXAFS (Fig. 7a and Additional file 1: Table S2), which is a bulk species characterization technique [100]. The contribution of sorbed $\mathrm{Mn}$ (II) to the Mn L-edge NEXAFS signal is determined by dividing the surface thickness $(\sim 3 \mathrm{~nm})$ by the mean particle diameter of HMO (309 nm; Table 1), which is $<1 \%$ of the total signal. Thus, the $\mathrm{O}$ horizon leachate not only reductively dissolved a fraction of the HMO, but also induced Mn reduction in the residual HMO. Manganese(II)-induced reductive dissolution of $\mathrm{HMO}$ at $\mathrm{pH} 5$ does not cause a $\mathrm{Mn}$ speciation change of the residual HMO [101]. Therefore, the observed Mn reduction of the residual HMO in our system implicates DOM as the more probable reductant of HMO. Further work remains to discern the relative contributions of $\mathrm{DOM}$ and $\mathrm{Mn}$ (II) to the reductive dissolution of HMO. Overall, the differential DOM sorption behavior of HMO and goethite, and the exhibited differences in mineral stability in the presence of DOM and $\mathrm{Mn}(\mathrm{II})$ in the $\mathrm{O}$ horizon leachate may have implications for DOM partitioning and lability in forest soils.

\section{Extent of DOM sorption, desorption, and biodegradability}

Sorption and desorption of DOM regulate the availability of organic $\mathrm{C}$ for microbial decomposition into assimilable substrates and ultimately into $\mathrm{CO}_{2}$ [3]. Extent and reversibility of DOM retention by minerals is therefore of great importance for soil $\mathrm{C}$ cycling. Here we show differential DOM sorption extent for HMO and goethite depending on the DOM concentration present. Goethite exhibits stronger sorption-and reaches saturation-of DOM at lower initial $\mathrm{C}$ :( $\mathrm{Mn}$ or $\mathrm{Fe}$ ) molar ratios than does HMO, and $\mathrm{HMO}$ has a greater maximum DOM sorption capacity $\left(88 \pm 1 \mathrm{mg} \mathrm{C} \mathrm{g}^{-1}\right.$ versus $67 \pm 1 \mathrm{mg} \mathrm{C} \mathrm{g}^{-1}$ ) (Figs. 6 and Additional file 1: Figure S8). Goethite has a strong affinity for carboxylic $\mathrm{C}$ and select polysaccharide-associated functional groups at low initial C:Fe molar ratios (Fig. 2c), whereas HMO has a sustained increase in sorption of polysaccharide-associated $\mathrm{C}$ over a wider range of initial C:metal molar ratio (Fig. 1c).

Differential DOM sorption behavior cannot be attributed to initial SSA in this case, as the HMO and goethite tested have virtually the same SSA $\left(138-140 \mathrm{~m}^{2} \mathrm{~g}^{-1}\right)$ (Table 1). The SSA-normalized DOM sorption maxima for HMO and goethite are $6.4 \times 10^{2}$ and $4.8 \times 10^{2} \mu \mathrm{g}$ $\mathrm{C} \mathrm{m}^{-2}$, respectively (Fig. 6). Reported values for DOM sorption onto goethite $\left(\mathrm{N}_{2}\right.$-BET SSA $\left.=47-73 \mathrm{~m}^{2} \mathrm{~g}^{-1}\right)$ at $\mathrm{pH} 4$ range from $2 \times 10^{2}$ to $1.9 \times 10^{3} \mu \mathrm{g} \mathrm{C} \mathrm{m}^{-2}$ depending on the chemical composition of the DOM $[4,13,89,102]$. A more crystalline goethite $\left(\mathrm{N}_{2}\right.$-BET SSA $=50.1 \pm 0.1 \mathrm{~m}^{2} \mathrm{~g}^{-1}$ ) than that used in our study more strongly sorbed oak-derived DOM than did a more crystalline $\delta-\mathrm{MnO}_{2}$ (birnessite; $\mathrm{N}_{2}$ - $\mathrm{BET}$ $\mathrm{SSA}=83.8 \pm 0.7 \mathrm{~m}^{2} \mathrm{~g}^{-1}$ ) at all DOM concentrations tested at $\mathrm{pH} 4$ [13], making DOM sorption inversely related to the initial mineral SSA in this case.

Nevertheless, applying the $\mathrm{N}_{2}$-BET method, which measures external SSA only, to the DOM-mineral sorption complexes helps to explain differential DOM sorption behavior by HMO and goethite (Figs. 6a and Additional file 1: Figure S9). Over an initial C:Fe molar ratio of $0-0.92$, DOM sorption onto goethite increases sharply, coinciding with a sharp decrease in $\mathrm{N}_{2}$-BET SSA, whereas both DOM sorption and $\mathrm{N}_{2}$-BET SSA 
remain relatively constant at higher initial C:Fe molar ratios (Figs. 6a and Additional file 1: Figure S9). Thus, DOM appears to saturate and decrease the available surface area at a low $\mathrm{C}$ loading. In contrast, increasing DOM sorption does not have a clear impact on $\mathrm{N}_{2}$-BET SSA over the corresponding initial C:Mn molar ratio of 0-0.92 (Figs. 6a and Additional file 1: Figure S9). Thus, internal surfaces of $\mathrm{HMO}$ are evidently contributing to DOM sorption, as has been observed for As(III) sorption $[61,75]$, and attenuating the decrease in $\mathrm{N}_{2}$-BET SSA that is observed for goethite.

Ferrihydrite, a poorly crystalline $\mathrm{Fe}$ oxide, has a greater SSA $\left(280 \mathrm{~m}^{2} \mathrm{~g}^{-1}\right)$ than goethite, HMO, and birnessite, and has greater maximum capacity to sorb DOM extracted from the same Stroud Water Research Center site $\left(7.2 \times 10^{2} \mu \mathrm{g} \mathrm{C} \mathrm{m}^{-2}\right.$ at pH 7 and $8.5 \times 10^{2} \mu \mathrm{g} \mathrm{C} \mathrm{m}^{-2}$ at $\mathrm{pH}$ 4) [63]. Reported values for DOM sorption onto ferrihydrite at $\mathrm{pH} 4-4.6$ range from $5.1 \times 10^{2}$ to $1.1 \times 10^{3} \mu \mathrm{g} \mathrm{C} \mathrm{m}^{-2}[102,103]$. Overall, relative contributions of Mn oxides and Fe oxides to DOM sorption in soils will depend on several factors including the relative abundance of the specific phases present, the DOM concentration and chemical composition, as well as $\mathrm{pH}$. Under acidic conditions, we may expect sorption extent to follow the following mineral hierarchy for $\mathrm{O}$ horizon extracted DOM: ferrihydrite $>(\mathrm{HMO}$, goethite $)>$ birnessite, where HMO increases in contribution to DOM sorption relative to goethite in environments with higher DOM concentrations.

Indeed, the concentration of DOM sorbed onto the solid-phase plays an important role in the extent of $\mathrm{C}$ desorption as well. In the case of $\mathrm{HMO}, \% \mathrm{C}$ desorption is lower for a $\mathrm{C}$ loading significantly below the sorption maximum compared to \% $\mathrm{C}$ desorption at $\mathrm{C}$ loadings at or near the sorption maximum (Fig. 6). In other words, HMO binds DOM more strongly at low $C$ loadings, probably due to ample available binding sites. Likewise, increasing sorbed DOM concentrations on ferrihydrite leads to an increase in the $\% \mathrm{C}$ desorption at $\mathrm{pH} 4$ and $\mathrm{pH}$ 7 , potentially due to a relative increase in association of DOM with ferrihydrite pores at lower C:Fe ratios and/or the relative increase in bonding between DOM carboxyl groups and the ferrihydrite surface [63].

For the $\mathrm{C}$ loading range tested, we do not observe significant changes in \% $\mathrm{C}$ desorption from goethite. For instance, increasing $\mathrm{C}$ loading onto goethite from $2.1 \times 10^{2}$ to $4.8 \times 10^{2} \mu \mathrm{g} \mathrm{C} \mathrm{m}^{-2}$ does not significantly change the \% $\mathrm{C}$ desorption within the error of our measurements (Fig. 6). However, in another study, about $60 \%$ $\mathrm{C}$ desorption by $0.1 \mathrm{M} \mathrm{NaH}_{2} \mathrm{PO}_{4}$ is observed for goethite at a lower $\mathrm{C}$ loading $\left(3 \times 10^{1} \mu \mathrm{g} \mathrm{C} \mathrm{m}^{-2}\right)$ [15], and decreases to $<30 \% \mathrm{C}$ desorbed at higher DOM loadings $\left(9 \times 10^{2}-1.9 \times 10^{3} \mu \mathrm{g} \mathrm{C} \mathrm{m}^{-2}\right)$ [4]. Decreasing \% C desorption with increasing DOM loadings may result from enhanced repulsion of the competing $\mathrm{H}_{2} \mathrm{PO}_{4}{ }^{-}$by nonbinding ligands, preferential binding of strongly sorbing DOM moieties, and/or the increased concentration of metal cations capable of forming metal bridges between the DOM and mineral surfaces $[15,104,105]$.

At a comparable lower $C$ loading range $\left(1.9 \times 10^{2}-\right.$

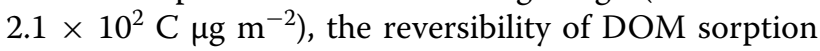
is greater for goethite than for HMO. At a comparable higher $\mathrm{C}$ loading $\left(4 \times 10^{2} \mu \mathrm{g} \mathrm{C} \mathrm{m}{ }^{-2}\right)$, the reversibility of DOM sorption onto HMO and onto goethite is not significantly different in the presence of $0.1 \mathrm{M} \mathrm{NaH}_{2} \mathrm{PO}_{4}$ (Fig. 6). Therefore, the chemical lability of HMO-sorbed DOM is lower than that of goethite-sorbed DOM at low C loadings in the presence of $\mathrm{H}_{2} \mathrm{PO}_{4}{ }^{-}$, but is similar at higher $\mathrm{C}$ loadings, though DOM lability in this high electrolyte solution may or may not accurately reflect lability in natural soil porewater. Importantly, the $0.1 \mathrm{M}$ $\mathrm{NaH}_{2} \mathrm{PO}_{4}$ extraction assesses the chemical lability of the sorbed DOM remaining at the end of the $24 \mathrm{~h}$ sorption study, and does not address the lability of the sorbed DOM that may have been released by the HMO reductive dissolution process.

Increased desorption of DOM in the form of extracellular polymeric substances (EPS) from EPS- $\mathrm{Al}(\mathrm{OH})_{3}$ complexes correlates with an increase in biodegradation of EPS associated with $\mathrm{Al}(\mathrm{OH})_{3}$, suggesting that desorption enhances microbial utilization of DOM [106]. Thus, the efficacy that $\mathrm{Fe}$ and $\mathrm{Al}$ oxides show in protecting DOM against microbial decomposition $[8,18,22]$ may extend to Mn oxides. The impact of HMO on the biodegradation of sorbed DOM has not been tested to the best of our knowledge. However, we show that the DOM remaining in solution after DOM sorption onto HMO and goethite has reached steady state (i.e., the DOM solution remaining after the $24 \mathrm{~h}$ DOM sorption experiment) is as biodegradable as unreacted DOM (Fig. 10). Thus, any chemical fractionation that HMO and goethite exert on DOM does not impact the biodegradability of DOM in the solution phase. Any significant impact that $\mathrm{HMO}$ and goethite have on DOM protection against microbial decomposition evidently would be limited to sorbed DOM. The relative impacts of HMO and goethite of biodegradability of sorbed DOM warrant future study.

\section{Conclusion}

Manganese cycling plays a central role in fungi-promoted oxidation of $\mathrm{O}$ horizon material through the first several years of decomposition, after which time the Mn partitions to Mn oxides [24]. We show that reaction with $\mathrm{O}$ horizon leachate drives significant $\mathrm{Mn}$ reduction of $\mathrm{HMO}$, a Mn oxide similar to biogenic Mn oxides. Manganese reduction of HMO may be driven by DOM and/or 
$\mathrm{Mn}(\mathrm{II})$ in the leachate. However, the observed Mn reduction of the residual HMO suggests that DOM is the more probable reductant over $\mathrm{Mn}$ (II) [101]. Whereas Fe and $\mathrm{Al}$ oxides appear to protect DOM from microbial decomposition through sorption or aqueous complex formation [8, $18,19]$, the greater susceptibility to dissolution of HMO in the presence of $\mathrm{O}$ horizon leachate-whether due to DOM and/or aqueous $\mathrm{Mn}(\mathrm{II})$ - suggests $\mathrm{Mn}$ oxides may not be a long term protector of organic $\mathrm{C}$ in near-surface forest soils. Dissolved organic matter-induced Mn oxide dissolution may promote repartitioning of DOM into the aqueous phase, increasing the vulnerability of DOM to microbial attack relative that sorbed to minerals surfaces. Nevertheless - and contrary to our hypothesis-we show that residual HMO after partial reductive dissolution has a stronger maximum DOM sorption capacity than that of goethite. In contrast, birnessite, a common Mn oxide in soils [107], has a weak sorption capacity for DOM relative to goethite [13]. Further, at a low C loading $\left(2 \times 10^{2} \mu \mathrm{g} \mathrm{m}^{-2}\right)$, DOM sorption is less reversible on HMO relative to goethite. Taken together, these observations suggest some $\mathrm{Mn}$ oxide phases may have a stronger capacity to regulate $\mathrm{C}$ partitioning in soils than previously recognized.

Much of the research on DOM sorption to mineral surfaces has been conducted using humic and fulvic acids. Previous work shows that water-extracted natural DOM, as in our O horizon leachate, contains $56 \%$ acidic humic substances-92\% of which is fulvic acid with the remaining $8 \%$ being humic acid [86]. Both natural DOM and fulvic acid (Suwannee River standard) adsorb to goethite through ligand exchange with carboxylic acid groups, as we observed with DOM in this study [85]. Thus, the DOM in this study and fulvic acids may have partially overlapping chemical signatures and similar sorption behavior on metal oxides, though the biodegradability of the two DOM forms may be distinct [3]. Contrary to our hypothesis, we show that $24 \mathrm{~h}$ reaction with $\mathrm{HMO}$ does not enhance the biodegradability of DOM in the dissolved phase relative to unreacted DOM. Overall, the net ecosystem control that secondary minerals exert on organic $\mathrm{C}$ partitioning will be a function of the specific minerals present and warrants further exploration.

\section{Additional file}

Additional file 1. Figures and Tables.

\footnotetext{
Abbreviations

Al: aluminum; ATR-FTIR: attenuated total reflectance-Fourier transform infrared spectroscopy; BDOC: biodegradable dissolved organic carbon; BET: BrunauerEmmett-Teller; C: carbon; DOC: dissolved organic carbon; DOM: dissolved organic matter; Fe: iron; HMO: hydrous manganese oxide; ICP-OES: inductively coupled plasma-optical emission spectroscopy; $\mathrm{Mn}$ : manganese; PZC: point
}

of zero charge; STXM-NEXAFS: scanning transmission X-ray microscopy-nearedge X-ray absorption fine structure spectroscopy; XPS: X-ray photoelectron spectroscopy; XRD: X-ray diffraction.

\section{Authors' contributions}

JWS conducted the experiments, performed data analysis and interpretation, and was the primary author for the manuscript. CG performed XPS analyses and data interpretation with consultation from TPB. JW assisted with STXMNEXAFS data collection, and performed STXM-NEXAFS data processing and interpretation. LAK assisted with experimental design and data interpretation of the bioreactor studies. PV assisted with performing the sorption and desorption studies. DLS guided the overall goals of the research project and provided research ideas. All authors read and approve the final manuscript.

\section{Author details \\ ${ }^{1}$ Biology Department, Multnomah University, Portland, OR 97220, USA. \\ ${ }^{2}$ Department of Plant \& Soil Sciences and Delaware Environmental Institute, University of Delaware, Newark, DE 19716, USA. ${ }^{3}$ Department of Chemistry and Biochemistry, University of Delaware, Newark, DE 19716, USA. ${ }^{4}$ Canadian Light Source Inc., University of Saskatchewan, Saskatoon, SK S7N 2V3, Canada. ${ }^{5}$ Stroud Water Research Center, 970 Spencer Road, Avondale, PA 19311, USA. ${ }^{6}$ Delaware Environmental Institute, University of Delaware, Newark, DE 19716, USA.}

\section{Acknowledgements}

We wish to thank G. Piorier for analytical support, J. Hendricks for logistical support, and M. Gentile and S. Roberts for providing technical assistance with the bioreactor studies.

\section{Competing interests}

The authors declare they have no competing interests.

\section{Availability of data and materials}

The datasets supporting the conclusions of this article are included within the article and its additional file. Further information may be shared by contacting the corresponding author.

\section{Ethics approval and consent to participate} Not applicable.

\section{Funding}

This research was funded by the Delaware Environmental Institute. Portions of this research were performed at the SM beamline of the Canadian Light Source, which is supported by the Natural Sciences and Engineering Research Council of Canada, the National Research Council of Canada, the Canadian Institutes of Health Research, the Province of Saskatchewan, Western Economic Diversification Canada, and the University of Saskatchewan. XPS instrument support at University of Delaware's SAF was provided in part by NSF 1428149. Bioreactor studies at the Stroud Water Research Center were supported, in part, by NSF 1452039 to LAK.

\section{Publisher's Note}

Springer Nature remains neutral with regard to jurisdictional claims in published maps and institutional affiliations.

Received: 12 November 2017 Accepted: 6 February 2018

Published online: 13 February 2018

\section{References}

1. Petit J-R, Jouzel J, Raynaud D, Barkov NI, Barnola J-M, Basile I et al (1999) Climate and atmospheric history of the past 420,000 years from the Vostok ice core, Antarctica. Nature. 399(6735):429-436

2. Gleixner $G$ (2013) Soil organic matter dynamics: a biological perspective derived from the use of compound-specific isotopes studies. Ecol Res 28(5):683-695

3. Lehmann J, Kleber M (2015) The contentious nature of soil organic matter. Nature 528(7580):60-68 
4. Kaiser K, Guggenberger G (2007) Sorptive stabilization of organic matter by microporous goethite: sorption into small pores vs. surface complexation. Eur J Soil Sci 58(1):45-59

5. Keil R, Mayer L (2014) Mineral matrices and organic matter. Treatise Geochem 12:337-359

6. Mikutta R, Kleber M, Torn MS, Jahn R (2006) Stabilization of soil organic matter: association with minerals or chemical recalcitrance? Biogeochemistry 77(1):25-56

7. Torn MS, Trumbore SE, Chadwick OA, Vitousek PM, Hendricks DM (1997) Mineral control of soil organic carbon storage and turnover. Nature 389(6647):170-173

8. Heckman K, Grandy A, Gao X, Keiluweit M, Wickings K, Carpenter K et al (2013) Sorptive fractionation of organic matter and formation of organo-hydroxy-aluminum complexes during litter biodegradation in the presence of gibbsite. Geochim Cosmochim Acta 121:667-683

9. Kögel-Knabner I, Guggenberger G, Kleber M, Kandeler E, Kalbitz K, Scheu S et al (2008) Organo-mineral associations in temperate soils: integrating biology, mineralogy, and organic matter chemistry. J Plant Nutr Soil Sci 171(1):61-82

10. Kaiser K, Eusterhues K, Rumpel C, Guggenberger G, Kogel-Knabner I (2002) Stabilization of organic matter by soil minerals -investigations of density and particle-size fractions from two acid forest soils. J Plant Nutr Soil Sci Z Pflanzenernahr Bodenkd. 165(4):451-459

11. Kleber M, Sollins P, Sutton R (2007) A conceptual model of organo-mineral interactions in soils: self-assembly of organic molecular fragments into zonal structures on mineral surfaces. Biogeochemistry 85(1):9-24

12. Mv Lützow, Kögel-Knabner I, Ekschmitt K, Matzner E, Guggenberger G, Marschner B et al (2006) Stabilization of organic matter in temperate soils: mechanisms and their relevance under different soil conditionsa review. Eur J Soil Sci 57(4):426-445

13. Chorover J, Amistadi MK (2001) Reaction of forest floor organic matter at goethite, birnessite and smectite surfaces. Geochim Cosmochim Acta 65(1):95-109

14. Kaiser K, Guggenberger G, Zech W (1996) Sorption of DOM and DOM fractions to forest soils. Geoderma 74(3-4):281-303

15. Kaiser K, Zech W (1999) Release of natural organic matter sorbed to oxides and a subsoil. Soil Sci Soc Am J 63(5):1157-1166

16. Mikutta R, Schaumann GE, Gildemeister D, Bonneville S, Kramer MG, Chorover J et al (2009) Biogeochemistry of mineral-organic associations across a long-term mineralogical soil gradient (0.3-4100 kyr), Hawaiian Islands. Geochim Cosmochim Acta 73(7):2034-2060

17. Thaymuang W, Kheoruenromne I, Suddhipraharn A, Sparks DL (2013) The role of mineralogy in organic matter stabilization in tropical soils. Soil Sci 178(6):308-315

18. Eusterhues K, Neidhardt J, Hädrich A, Küsel K, Totsche KU (2014) Biodegradation of ferrihydrite-associated organic matter. Biogeochemistry 119(1-3):45-50

19. Heckman K, Vazquez-Ortega A, Gao X, Chorover J, Rasmussen C (2011) Changes in water extractable organic matter during incubation of forest floor material in the presence of quartz, goethite and gibbsite surfaces. Geochim Cosmochim Acta 75(15):4295-4309

20. Schoonen MA (2004) Mechanisms of sedimentary pyrite formation. In: Amend JP, Edwards KJ, Lyons TW (eds) Sulfur biogeochemistry—past and present 379. Geological Society of America, Boulder, pp 117-134

21. Scheel T, Dörfler C, Kalbitz K (2007) Precipitation of dissolved organic matter by aluminum stabilizes carbon in acidic forest soils. Soil Sci Soc Am J 71(1):64-74

22. Schneider MPW, Scheel T, Mikutta R, van Hees P, Kaiser K, Kalbitz K (2010) Sorptive stabilization of organic matter by amorphous Al hydroxide. Geochim Cosmochim Acta 74(5):1606-1619

23. Miltner A, Zech W (1998) Carbohydrate decomposition in beech litter as influenced by aluminium, iron and manganese oxides. Soil Biol Biochem 30(1):1-7

24. Keiluweit M, Nico P, Harmon ME, Mao J, Pett-Ridge J, Kleber M (2015) Long-term litter decomposition controlled by manganese redox cycling. Proc Natl Acad Sci 112(38):E5253-E5260

25. Miltner A, Zech W (1998) Beech leaf litter lignin degradation and transformation as influenced by mineral phases. Org Geochem 28(7):457-463

26. Rennert T, Händel M, Höschen C, Lugmeier J, Steffens M, Totsche K (2014) A NanoSIMS study on the distribution of soil organic matter, iron and manganese in a nodule from a Stagnosol. Eur J Soil Sci 65(5):684-692

27. Estes E, Andeer P, Nordlund D, Wankel S, Hansel C (2016) Biogenic manganese oxides as reservoirs of organic carbon and proteins in terrestrial and marine environments. Geobiology. 15:158-172

28. Prescott CE (2010) Litter decomposition: what controls it and how can we alter it to sequester more carbon in forest soils? Biogeochemistry 101(1-3):133-149

29. Aponte C, García LV, Maranon T (2012) Tree species effect on litter decomposition and nutrient release in mediterranean oak forests changes over time. Ecosystems 15(7):1204-1218

30. Berg B, Davey M, De Marco A, Emmett B, Faituri M, Hobbie S et al (2010) Factors influencing limit values for pine needle litter decomposition: a synthesis for boreal and temperate pine forest systems. Biogeochemistry 100(1-3):57-73

31. Berg B, Steffen K, McClaugherty C (2007) Litter decomposition rate is dependent on litter Mn concentrations. Biogeochemistry 82(1):29-39

32. Davey MP, Berg B, Emmett BA, Rowland P (2007) Decomposition of oak leaf litter is related to initial litter Mn concentrations. Botany 85(1):16-24

33. De Marco A, Spaccini R, Vittozzi P, Esposito F, Berg B, De Santo AV (2012) Decomposition of black locust and black pine leaf litter in two coeval forest stands on Mount Vesuvius and dynamics of organic components assessed through proximate analysis and NMR spectroscopy. Soil Biol Biochem 51:1-15

34. Heim A, Frey B (2004) Early stage litter decomposition rates for Swiss forests. Biogeochemistry 70(3):299-313

35. Klotzbücher T, Kaiser K, Guggenberger G, Gatzek C, Kalbitz K (2011) A new conceptual model for the fate of lignin in decomposing plant litter. Ecology 92(5):1052-1062

36. Meentemeyer V (1978) Macroclimate and lignin control of litter decomposition rates. Ecology 59(3):465-472

37. Trum F, Titeux H, Cornelis J-T, Delvaux B (2011) Effects of manganese addition on carbon release from forest floor horizons. Can J For Res 41(3):643-648

38. Mukhopadhyay MJ, Sharma A (1991) Manganese in cell metabolism of higher plants. Bot Rev 57(2):117-149

39. Preston CM, Nault JR, Trofymow J, Smyth C, Group CW (2009) Chemical changes during 6 years of decomposition of 11 litters in some Canadian forest sites. Part 1. Elemental composition, tannins, phenolics, and proximate fractions. Ecosystems 12(7):1053-1077

40. Hofrichter M (2002) Review: lignin conversion by manganese peroxidase (MnP). Enzym Microbial Technol 30(4):454-466

41. Hansel CM, Zeiner CA, Santelli CM, Webb SM (2012) Mn(II) oxidation by an ascomycete fungus is linked to superoxide production during asexual reproduction. Proc Natl Acad Sci 109(31):12621-12625

42. Thompson IA, Huber DM, Guest CA, Schulze DG (2005) Fungal manganese oxidation in a reduced soil. Environ Microbiol 7(9):1480-1487

43. Herndon EM, Martínez CE, Brantley SL (2014) Spectroscopic (XANES/ XRF) characterization of contaminant manganese cycling in a temperate watershed. Biogeochemistry 121(3):505-517

44. Sunda WG, Kieber DJ (1994) Oxidation of humic substances by manganese oxides yields low-molecular-weight organic substrates. Nature 367:62-64

45. Stone AT, Morgan JJ (1984) Reduction and dissolution of manganese(III) and manganese(IV) oxides by organics: 2 . Survey of the reactivity of organics. Environ Sci Technol 18(8):617-624

46. Stone AT (1987) Microbial metabolites and the reductive dissolution of manganese oxides: oxalate and pyruvate. Geochim Cosmochim Acta 51(4):919-925

47. Hardie A, Dynes J, Kozak L, Huang P (2007) Influence of polyphenols on the integrated polyphenol-maillard reaction humification pathway as catalyzed by birnessite. Annal Environ Sci 1(1):11

48. Hardie AG, Dynes JJ, Kozak LM, Huang P (2009) Biomolecule-induced carbonate genesis in abiotic formation of humic substances in nature. Can J Soil Sci 89(4):445-453

49. Hardie AG, Dynes JJ, Kozak LM, Huang PM (2009) The role of glucose in abiotic humification pathways as catalyzed by birnessite. J Mol Catal Chem 308(1-2):114-126

50. Hardie AG, Dynes JJ, Kozak LM, Huang PM, editors (2010) Abiotic catalysis of the Maillard reaction and polyphenol-Maillard humification pathways by Al, Fe and Mn oxides. In: Proceedings of the 19th world 
congress of soil science: soil solutions for a changing world, Brisbane, Australia, 1-6 August 2010. International Union of Soil Sciences (IUSS), c/o Institut für Bodenforschung, Universität für Bodenkultur

51. Liu M-M, Cao X-H, Tan W-F, Feng X-H, Qiu G-H, Chen X-H et al (2011) Structural controls on the catalytic polymerization of hydroquinone by birnessites. Clays Clay Miner 59(5):525-537

52. Li C, Zhang B, Ertunc T, Schaeffer A, Ji R (2012) Birnessite-induced binding of phenolic monomers to soil humic substances and nature of the bound residues. Environ Sci Technol 46(16):8843-8850

53. Waite TD, Wrigley IC, Szymczak R (1988) Photoassisted dissolution of a colloidal manganese oxide in the presence of fulvic acid. Environ Sci Technol 22(7):778-785

54. Johnson K, Purvis G, Lopez-Capel E, Peacock C, Gray N, Wagner T et al (2015) Towards a mechanistic understanding of carbon stabilization in manganese oxides. Nat Commun 6(7628):1-11

55. Mikutta R, Mikutta C, Kalbitz K, Scheel T, Kaiser K, Jahn R (2007) Biodegradation of forest floor organic matter bound to minerals via different binding mechanisms. Geochim Cosmochim Acta 71(10):2569-2590

56. Tamura H, Goto K, Yotsuyanagi T, Nagayama M (1974) Spectrophotometric determination of iron(II) with 1,10-phenanthroline in the presence of large amounts of iron (III). Talanta 21(4):314-318

57. Villalobos M, Toner B, Bargar J, Sposito G (2003) Characterization of the manganese oxide produced by Pseudomonas putida strain MnB1. Geochim Cosmochim Acta 67(14):2649-2662

58. Fendorf SE, Zasoski RJ (1992) Chromium(III) oxidation by delta-MnO ${ }_{2} .1$. Characterization. Environ Sci Technol 26(1):79-85

59. Gadde RR, Laitlinen HA (1974) Studies of heavy metal adsorption on hydrous iron and manganese oxides. Anal Chem 46:2022-2026

60. Schwertmann U, Cornell RM (2000) Iron oxides in the laboratory. Second, completely revised and extended. Wiley, Weinheim, p 188

61. Lafferty BJ, Ginder-Vogel M, Sparks DL (2010) Arsenite oxidation by a poorly crystalline manganese-oxide 1, stirred-flow experiments. Environ Sci Technol. 44(22):8460-8466

62. Brunauer S, Emmett PH, Teller E (1938) Adsorption of gases in multimolecular layers. J Am Chem Soc 60(2):309-319

63. Chen C, Dynes JJ, Wang J, Sparks DL (2014) Properties of Fe-organic matter associations via coprecipitation versus adsorption. Environ Sci Technol 48:13751-13759

64. Tan W-F, Lu S-J, Liu F, Feng X-H, He J-Z, Koopal LK (2008) Determination of the point-of-zero charge of manganese oxides with different methods including an improved salt titration method. Soil Sci 173(4):277-286

65. Kaplan LA, Newbold JD (1995) Measurement of streamwater biodegradable dissolved organic carbon with a plug-flow bioreactor. Water Res 29(12):2696-2706

66. Powel C, Jablonski A (2010) NIST electron inelastic-mean-free-path database, Version 1.2, SRD 71. National Institute of Standards and Technology, Gaithersburg

67. Taylor A (1990) Practical surface analysis. Auger and X-ray photoelectron spectroscopy, vol 1, 2nd edn. Wiley, New York, p 1367

68. Gerin PA, Genet M, Herbillon A, Delvaux B (2003) Surface analysis of soil material by X-ray photoelectron spectroscopy. Eur I Soil Sci 54(3):589-604

69. Mikutta R, Lorenz D, Guggenberger G, Haumaier L, Freund A (2014) Properties and reactivity of Fe-organic matter associations formed by coprecipitation $<i>$ versus $</ i>$ adsorption: clues from arsenate batch adsorption. Geochim Cosmochim Acta 144:258-276

70. Ilton ES, Post JE, Heaney PJ, Ling FT, Kerisit SN (2016) XPS determination of Mn oxidation states in Mn (hydr) oxides. Appl Surf Sci 366:475-485

71. Hitchcock A, Tyliszczak T, Obst M, Swerhone G, Lawrence J (2010) Improving sensitivity in soft X-ray STXM using low energy X-ray fluorescence. Microsc Microanal 16(S2):924-925

72. Hitchcock A (2000) aXis-2000 is an IDL-based analytical package. http:// unicorn.memaster.ca

73. Gilbert B, Frazer B, Belz A, Conrad P, Nealson K, Haskel D et al (2003) Multiple scattering calculations of bonding and $X$-ray absorption spectroscopy of manganese oxides. J Phys Chem A 107(16):2839-2847

74. Zhou J, Wang J, Fang H, Wu C, Cutler JN, Sham TK (2010) Nanoscale chemical imaging and spectroscopy of individual RuO 2 coated carbon nanotubes. Chem Commun 46(16):2778-2780
75. Lafferty BJ, Ginder-Vogel M, Zhu MQ, Livi KJT, Sparks DL (2010) Arsenite oxidation by a poorly crystalline manganese-oxide. 2. Results from X-ray absorption spectroscopy and X-ray diffraction. Environ Sci Technol 44(22):8467-8472

76. Larsen O, Postma D (2001) Kinetics of reductive bulk dissolution of lepidocrocite, ferrihydrite, and goethite. Geochim Cosmochim Acta 65(9):1367-1379

77. Kogelmann WJ, Sharpe WE (2006) Soil acidity and manganese in declining and nondeclining sugar maple stands in Pennsylvania. J Environ Qual 35(2):433-441

78. Kloster N, Avena M (2015) Interaction of humic acids with soil minerals: adsorption and surface aggregation induced by $\mathrm{Ca}_{2}{ }^{+}$. Environ Chem 12(6):731-738

79. Kloster N, Brigante M, Zanini G, Avena M (2013) Aggregation kinetics of humic acids in the presence of calcium ions. Colloids Surf A 427:76-82

80. Miller D, Biesinger M, McIntyre N (2002) Interactions of $\mathrm{CO}_{2}$ and $\mathrm{CO}$ at fractional atmosphere pressures with iron and iron oxide surfaces: one possible mechanism for surface contamination? Surf Interface Anal 33(4):299-305

81. Piao H, Mcintyre NS (2002) Adventitious carbon growth on aluminium and gold-aluminium alloy surfaces. Surf Interface Anal 33(7):591-594

82. Zubavichus Y, Fuchs O, Weinhardt L, Heske C, Umbach E, Denlinger JD et al (2004) Soft X-ray-induced decomposition of amino acids: an XPS, mass spectrometry, and NEXAFS study. Radiat Res 161(3):346-358

83. Sposito G (2008) The chemistry of soils. Oxford University Press, Oxford

84. Davis JA (1982) Adsorption of natural dissolved organic matter at the oxide/water interface. Geochim Cosmochim Acta 46(11):2381-2393

85. Gu B, Schmitt J, Chen Z, Liang L, McCarthy JF (1994) Adsorption and desorption of natural organic matter on iron oxide: mechanisms and models. Environ Sci Technol 28(1):38-46

86. Kaiser K, Guggenberger G, Haumaier L, Zech W (1997) Dissolved organic matter sorption on sub soils and minerals studied by 13C-NMR and DRIFT spectroscopy. Eur J Soil Sci 48(2):301-310

87. Barrow N, Shaw T (1975) The slow reactions between soil and anions: 2 . Effect of time and temperature on the decrease in phosphate concentration in the soil solution. Soil Sci 119(2):167-177

88. Kaplan LA, Wiegner TN, Newbold J, Ostrom PH, Gandhi H (2008) Untangling the complex issue of dissolved organic carbon uptake: a stable isotope approach. Freshw Biol 53(5):855-864

89. Kaiser K (2003) Sorption of natural organic matter fractions to goethite (a-FeOOH): effect of chemical composition as revealed by liquid-state 13C NMR and wet-chemical analysis. Org Geochem 34(11):1569-1579

90. Fu H, Quan X (2006) Complexes of fulvic acid on the surface of hematite, goethite, and akaganeite: FTIR observation. Chemosphere 63(3):403-410

91. Oren A, Chefetz B (2012) Sorptive and desorptive fractionation of dissolved organic matter by mineral soil matrices. J Environ Qual 41(2):526-533

92. Shen Y-H (1999) Sorption of natural dissolved organic matter on soil. Chemosphere 38(7):1505-1515

93. Kaiser K, Guggenberger G (2003) Mineral surfaces and soil organic matter. Eur J Soil Sci 54(2):219-236

94. Kingston F, Posner A, Quirk J (1972) Anion adsorption by goethite and gibbsite. J Soil Sci 23(2):177-192

95. Artz RR, Chapman SJ, Robertson AJ, Potts JM, Laggoun-Défarge F, Gogo S et al (2008) FTIR spectroscopy can be used as a screening too for organic matter quality in regenerating cutover peatlands. Soil Biol Biochem 40(2):515-527

96. Davis JA, Gloor R (1981) Adsorption of dissolved organics in lake water by aluminum oxide. Effect of molecular weight. Environ Sci Technol 15(10):1223-1229

97. Jardine P, McCarthy J, Weber N (1989) Mechanisms of dissolved organic carbon adsorption on soil. Soil Sci Soc Am J 53(5):1378-1385

98. Stone AT, Godtfredsen KL, Deng B (1994) Sources and reactivity of reductants encountered in aquatic environments. Chemistry of aquatic systems: Local and global perspectives. Springer, Berlin, pp 337-374

99. Suter D, Banwart S, Stumm W (1991) Dissolution of hydrous iron(III) oxides by reductive mechanisms. Langmuir 7(4):809-813

100. Guttmann P, Bittencourt C (2015) Overview of nanoscale NEXAFS performed with soft X-ray microscopes. Beilstein J Nanotechnol 6(1):595-604 
101. Elzinga EJ (2016) 54Mn radiotracers demonstrate continuous dissolution and reprecipitation of vernadite $\left(\delta-\mathrm{MnO}_{2}\right)$ during interaction with aqueous Mn(II). Environ Sci Technol 50(16):8670-8677

102. Kaiser K, Mikutta R, Guggenberger G (2007) Increased stability of organic matter sorbed to ferrihydrite and goethite on aging. Soil Sci Soc Am J 71(3):711-719

103. Eusterhues K, Rennert T, Knicker H, Kogel-Knabner I, Totsche KU, Schwertmann U (2011) Fractionation of organic matter due to reaction with ferrihydrite: coprecipitation versus adsorption. Environ Sci Technol 45(2):527-533

104. Edwards M, Benjamin MM, Ryan JN (1996) Role of organic acidity in sorption of natural organic matter (NOM) to oxide surfaces. Colloids Surf A 107:297-307
105. Kaiser K, Zech W (1997) Competitive sorption of dissolved organic matter fractions to soils and related mineral phases. Soil Sci Soc Am J 61(1):64-69

106. Mikutta R, Zang U, Chorover J, Haumaier L, Kalbitz K (2011) Stabilization of extracellular polymeric substances (Bacillus subtilis) by adsorption to and coprecipitation with Al forms. Geochim Cosmochim Acta 75(11):3135-3154

107. Taylor R, McKenzie R, Norrish K (1964) The mineralogy and chemistry of manganese in some Australian soils. Soil Res 2(2):235-248

\section{Submit your manuscript to a SpringerOpen ${ }^{\odot}$ journal and benefit from:}

- Convenient online submission

- Rigorous peer review

- Open access: articles freely available online

- High visibility within the field

- Retaining the copyright to your article

Submit your next manuscript at $\boldsymbol{\nabla}$ springeropen.com 